\title{
Mediterranean Diet to Prevent the Development of Colon Diseases: A Meta-Analysis of Gut Microbiota Studies
}

\author{
Oscar Illescas ${ }^{1} \mathbb{D}$, Miriam Rodríguez-Sosa ${ }^{2}$ and Manuela Gariboldi ${ }^{1, *}$ \\ 1 Genetic Epidemiology and Pharmacogenomics Unit, Department of Research, \\ Fondazione IRCCS Istituto Nazionale dei Tumori (INT), 20133 Milan, Italy; \\ oscarillescas.pomposo@istitutotumori.mi.it \\ 2 Unidad de Biomedicina, Facultad de Estudios Superiores Iztacala, Universidad Nacional Autónoma de \\ México (UNAM), Tlalnepantla C.P. 54090, MEX, Mexico; rodmir@unam.mx \\ * Correspondence: manuela.gariboldi@istitutotumori.mi.it; Tel.: +39-2-23902042
}

Citation: Illescas, O.; Rodríguez-

Sosa, M.; Gariboldi, M.

Mediterranean Diet to Prevent the Development of Colon Diseases: A Meta-Analysis of Gut Microbiota Studies. Nutrients 2021, 13, 2234.

https://doi.org/10.3390/nu13072234

Academic Editor: Jose V. Sorlí

Received: 1 June 2021

Accepted: 25 June 2021

Published: 29 June 2021

Publisher's Note: MDPI stays neutral with regard to jurisdictional claims in published maps and institutional affiliations.

Copyright: (c) 2021 by the authors. Licensee MDPI, Basel, Switzerland. This article is an open access article distributed under the terms and conditions of the Creative Commons Attribution (CC BY) license (https:/ / creativecommons.org/licenses/by/ $4.0 /)$.

\begin{abstract}
Gut microbiota dysbiosis is a common feature in colorectal cancer (CRC) and inflammatory bowel diseases (IBD). Adoption of the Mediterranean diet (MD) has been proposed as a therapeutic approach for the prevention of multiple diseases, and one of its mechanisms of action is the modulation of the microbiota. We aimed to determine whether MD can be used as a preventive measure against cancer and inflammation-related diseases of the gut, based on its capacity to modulate the local microbiota. A joint meta-analysis of publicly available $16 \mathrm{~S}$ data derived from subjects following MD or other diets and from patients with CRC, IBD, or other gut-related diseases was conducted. We observed that the microbiota associated with MD was enriched in bacteria that promote an anti-inflammatory environment but low in taxa with pro-inflammatory properties capable of altering intestinal barrier functions. We found an opposite trend in patients with intestinal diseases, including cancer. Some of these differences were maintained even when MD was compared to healthy controls without a defined diet. Our findings highlight the unique effects of MD on the gut microbiota and suggest that integrating MD principles into a person's lifestyle may serve as a preventive method against cancer and other gut-related diseases.
\end{abstract}

Keywords: microbiota; 16S; meta-analysis; Mediterranean diet; inflammation; adenoma; colorectal cancer

\section{Introduction}

The increased incidence and mortality of many cancers observed in the last few decades has been in part attributed to the modern and heavily industrialized lifestyle [1,2], characterized by environmental pollution, stress, sedentarism, and a diet dominated by pre-processed foods rich in fat, salt, meat, refined flour and sugar, and little to no fresh vegetables, fruits and nuts, such as the so-called Western-type or Westernized diet (WD) [3-5].

Lifestyle-changing therapeutic application of healthier dietary patterns has been considered effective, non-invasive, and long-lasting [6-8], and several diets have been proposed for the treatment or prevention of different diseases. One of the most widely used is the Mediterranean diet (MD). This term encompasses a series of dietary patterns used in countries of the Mediterranean coast, with shared common premises including high consumption of fresh vegetables, fruits, nuts, grains, legumes and olive oil, moderate to high consumption of fish, moderate consumption of dairy and wine, and low intake of meat and sweets [9]. The benefits of MD have recently been suggested on several pathologies, including cancer [10-13].

The modern Paleolithic diet (PD) is a different approach characterized by a high intake of vegetables, fruits, nuts, eggs, fish and meat, minimizing that of grains, cereals, legumes, dairy products, and processed foods [14]. Recently, it has sparked increasing interest due 
to its alleged beneficial effects on the prevention and treatment of diabetes, cancer, and cardiovascular diseases [15-18].

In terms of microbiota composition, both MD and PD reduce the consumption of simple sugars, animal fats, and processed foods compared to $\mathrm{WD}$, and this alone is known to have a potentially beneficial impact on microbiota and health [19-22]. However, MD differs from PD by including carbohydrate sources such as grains and legumes, which PD excludes, and by reducing the intake of animal-based protein, which has also been shown to influence the microbiota composition [23-26].

It has been postulated that many of the effects of dietary interventions are driven by the microbiota. Dietary components can shape the composition of the gut microbiota and modulate its metabolism [27], which in turn will affect the production of beneficial metabolites such as short-chain fatty acids (SCFA) and potentially toxic compounds such as procarcinogen trimethylamine (TMA), or also modulate the metabolism and immune response at the systemic and local level [28-32]. Under normal conditions, the microbiota provides metabolic pathways that interact and complement the host metabolism, helping to maintain normal organ function and nutrition while limiting the activity of pathogens.

Contrary to this normal state, the term dysbiosis refers to an imbalance in the composition and metabolism of the microbiota that has been associated with pro-inflammatory conditions and therefore has been suggested to contribute to the pathogenesis of various diseases, ranging from psychiatric diseases to metabolic disorders and cancer [31,33,34]. This imbalance and associated inflammation is often attributed to WD [3,4], and it plays an important role in the pathogenesis of inflammatory bowel diseases (IBD) such as Crohn's disease (CD) and ulcerative colitis (UC) as well as colorectal cancer (CRC) [35-37]. Importantly, in recent years, the incidence of all these diseases has increased in industrialized and newly industrialized countries [38,39].

Trying to define and describe the complex relations between diet, microbiota, and disease, several cross-sectional and interventional studies describing the microbiota associated with specific dietary patterns or diseases have been conducted. No attempt has yet been made to cross data from diet and disease studies to identify common or specific bacterial populations that could be proposed for preventing gut-related diseases.

We performed a joint meta-analysis of 16S RNA data from subjects on diets such as $\mathrm{MD}, \mathrm{PD}$, or $\mathrm{WD}$, and patients with intestinal diseases related to inflammation or cancer. We aimed to determine whether the microbiota composition linked to any of the diets may justify a possible preventive or therapeutic use of the diet. This is by finding the bacteria differently represented in each diet or disease and evaluating their reported health benefits or pathogenic functions.

\section{Materials and Methods}

\subsection{Data Acquisition and Inclusion Criteria}

The $16 \mathrm{~S}$ rRNA gene datasets included in the meta-analysis are publicly available and were identified through a literature search in NCBI PubMed [40] and in the Sequence Read Archive [41]. Search terms were "gut microbiota" or "16s" together with one of the following: "colitis", "IBD", “Crohn's disease", "colorectal cancer", "colon cancer", "colon adenoma", "adenoma", "colon polyp", “Mediterranean diet", “Western diet", “Westernized diet", "paleolithic diet", "fodmap", and "ketogenic diet". The search was limited to articles published from January 2008 to July 2020. When the study did not include a public availability statement, the corresponding author was contacted to ask for access to the data, but we did not include any studies that required additional ethics committee approvals or authorizations for access (e.g., controlled dbGaP studies). Inclusion criteria for all included datasets were as follows:

1. Cross-sectional studies or dietary interventions with $\mathrm{MD}, \mathrm{PD}$, or $\mathrm{WD}$, or case-control studies of intestinal diseases such as colorectal cancer (CRC), colon adenoma (CA), colon polyposis (CP), ulcerative colitis (UC), and Crohn's disease (CD). May include 
or not healthy subjects (HC), healthy familiars of IBD subjects (FC), or subjects at risk of developing CRC (RS).

2. Available 16s rRNA gene sequences derived from human feces with associated quality scores and metadata.

3. Samples obtained when subjects or patients were not under drug treatments.

4. Data from at least 10 patients, subjects following a defined diet or healthy subjects with a minimum of 6000 reads each.

\subsection{Study Groups}

Subjects from the obtained databases were assigned to different groups, defined according to the subject's dietary pattern and (or) diagnosed gastrointestinal disease. Either cross-sectional or interventional studies on MD, PD, and WD diets were included in the analysis. Diet composition and the main hallmarks of each diet were obtained directly from the included publications. WD featured a low content of fiber, fruits, and vegetables contrasted by a high consumption of refined carbohydrates and saturated fats [42]. PD was characterized by the consumption of vegetables, fruits, seeds, lean meat, eggs, and fish, the reduction of salt and refined sugars, and the exclusion of grains, pulses, and dairy products [43]. Adherence to MD was defined with validated scores [44,45].

Case-control cross-sectional studies and pre-treatment data from clinical trial reports on CRC, CA, CP, UC, and CD were included; guidelines for the diagnosis of all diseases are reported in the corresponding study. HC, FC, and RS subjects were obtained when available in any of the included studies, none of them followed any specific or controlled diet. HC and FC subjects were all healthy, RS subjects were defined as at risk of developing CRC after colonoscopy, had previous personal or familiar history of CRC, or presented obesity (BMI $\geq 30$, Table S2). None of the subjects in the HC, FC, or RS groups followed a defined diet. Additional studies $[27,46-48]$ were included with the intention of increasing the number of control subjects.

\subsection{Data Analysis and Statistics}

Raw sequences were processed and analyzed in QIIME 1.9.1 [49]. Sequences were quality filtered with Trimmomatic [50] by truncating when the average quality in a fourbase sliding window dropped below $\mathrm{Q}<25$. Surviving high-quality reads were sorted with 99\% similarity into operational taxonomy units (OTUs) with uclust [51] and aligned against the Greengenes 13.8 database with 97\% similarity using PyNAST [52,53]. Chimeric sequences were detected with ChimeraSlayer [54] and excluded from downstream analysis. This stringent processing and analysis resulted in several processed samples not meeting the initial inclusion criteria; therefore, samples with less than 6000 surviving reads and datasets with less than 10 subjects per group were dropped. OTUs with less than 10 reads were also discarded for further analyses.

All data were analyzed together and with the same parameters. Taxonomy assignment was performed with a widely used and trusted reference database covering all included variant regions of the 16s rRNA gene [53]. Sequences that failed to align to the database were not considered. Alpha diversity was assessed using Chao1 metric, total observed OTUs, and the Shannon diversity index. Significance of the test was determined with a nonparametric T-test, and $p$-values were corrected with the false discovery rate (FDR) method (Tables S1 and S2). Only comparisons presenting $p<0.001$ were considered significant. Beta diversity was estimated using Unifrac distance metrics [55]. Jackknife-supported Principal Coordinates Analyses (PCoA) were performed with QIIME and visualized with Past 4.03 [56] (Figures S3-S6). The significance of PCoA data separation was verified with a permutation test with pseudo-F ratios (function ADONIS) and an analysis of similarities (function ANOSIM) (Tables S3 and S4).

OTU representation was summarized at the phylum, family, and genus levels following the QIIME pipeline (Tables S5-S7); only fully annotated OTUs were considered for analysis. Fold change was calculated in all instances using the abundance of group $\mathrm{HC}$ as a 
reference. The Wilcoxon rank sum test was used to assess differentially represented OTUs; $p$-values were corrected for FDR and considered statistically significant when $p<0.01$ (Tables S6 and S8). All statistical analyses were performed in QIIME.

\section{Results}

A total of 168 clinical or observational studies on diet or gut diseases-associated microbiota, 42 of which included $16 \mathrm{~S}$ rRNA analysis, were initially identified. Datasets corresponding to 26 studies were available; two of them were discarded, as samples were not sufficiently annotated. Another seven studies did not reach the minimum threshold of 10 samples with at least 6000 quality-checked reads and were discarded.

The remaining 17 studies were included in the meta-analysis. Included datasets comprised 1931 human fecal samples for a total of $157,425,716$ reads; $80.9 \%$ of the samples (1563) and $95.7 \%$ of reads (150656411) survived the quality check and were used for the analyses. Samples were assigned to eleven different groups (Table 1 and Table S1).

Table 1. Groups included in the meta-analysis.

\begin{tabular}{|c|c|c|c|c|c|}
\hline Group ${ }^{1}$ & Diet & Disease Status & Subjects & Description & Studies \\
\hline $\mathrm{HC}$ & Undefined & No disease & 196 & Healthy subjects non-related to patients & {$[27,47,48,57-59]$} \\
\hline $\mathrm{FC}$ & Undefined & No disease & 54 & Healthy familiars of IBD patients & [60] \\
\hline RS & Undefined & No disease & 214 & Subjects at risk of CRC $^{2}$ & {$[44,57,61-63]$} \\
\hline WD & Western-type & No disease & 38 & Diet subjects. Healthy & [42] \\
\hline PD & Modern Paleolithic & No disease & 15 & Diet subjects. Healthy & [43] \\
\hline MD & Mediterranean & No disease & 123 & Diet subjects. Healthy & {$[61,62,64]$} \\
\hline $\mathrm{CP}$ & Undefined & Colon polyposis & 23 & Patients & [63] \\
\hline $\mathrm{CA}$ & Undefined & Colorectal adenoma & 662 & Patients & {$[57,63,65-67]$} \\
\hline CRC & Undefined & Colorectal cancer & 155 & Patients & {$[57,65,66]$} \\
\hline $\mathrm{UC}$ & Undefined & Ulcerative colitis & 38 & Patients & {$[59,60]$} \\
\hline $\mathrm{CD}$ & Undefined & Crohn's disease & 45 & Patients & [58-60] \\
\hline
\end{tabular}

${ }^{1}$ Groups: Healthy subjects (HC) and healthy familiars of IBD patients (FC). Subjects at risk of developing colorectal cancer (RS), patients with colon polyps (CP), colon adenoma (CA), colorectal cancer (CRC), Crohn's disease (CD), and ulcerative colitis patients (UC). Subjects following a Mediterranean (MD), modern Paleolithic (PD) or Western-like diet (WD). ${ }^{2}$ Further criteria information in Table S2.

\subsection{Alpha and Beta Diversity}

Alpha diversity presented no significant differences $(p<0.001)$ between either diet and disease groups or respect to the HC controls (Figures S1 and S2, Table S3).

Beta diversity components of groups HC, FC, and RS, observed in PCoA, presented no significant separation. Instead, MD distanced from WD, PD, HC, and RS groups. Likewise, CRC and CA formed separated clusters, which were partially segregated from RS and HC. UC and CD clustered together but remained separated from HC and FC. MD also segregated when confronted to CA, CRC, UC, and CD. In all cases, the separation was more evident with unweighted data, which only take into account the presence of OTUs, compared to weighted data, which consider both the presence and abundance of OTUs. (Figure 1, Figures S3-S8, Table S4). These distributions suggest that the microbiota composition of the subjects following MD is different from diseases and controls, and this effect is not shared by the other diets.

\subsection{Microbiota Composition Analysis}

Average proportional composition of all groups by phyla and genera can be found in Figure 2 and Tables 2 and 3; only significant differences $(p<0.01)$ were discussed (Tables S5-S7). 

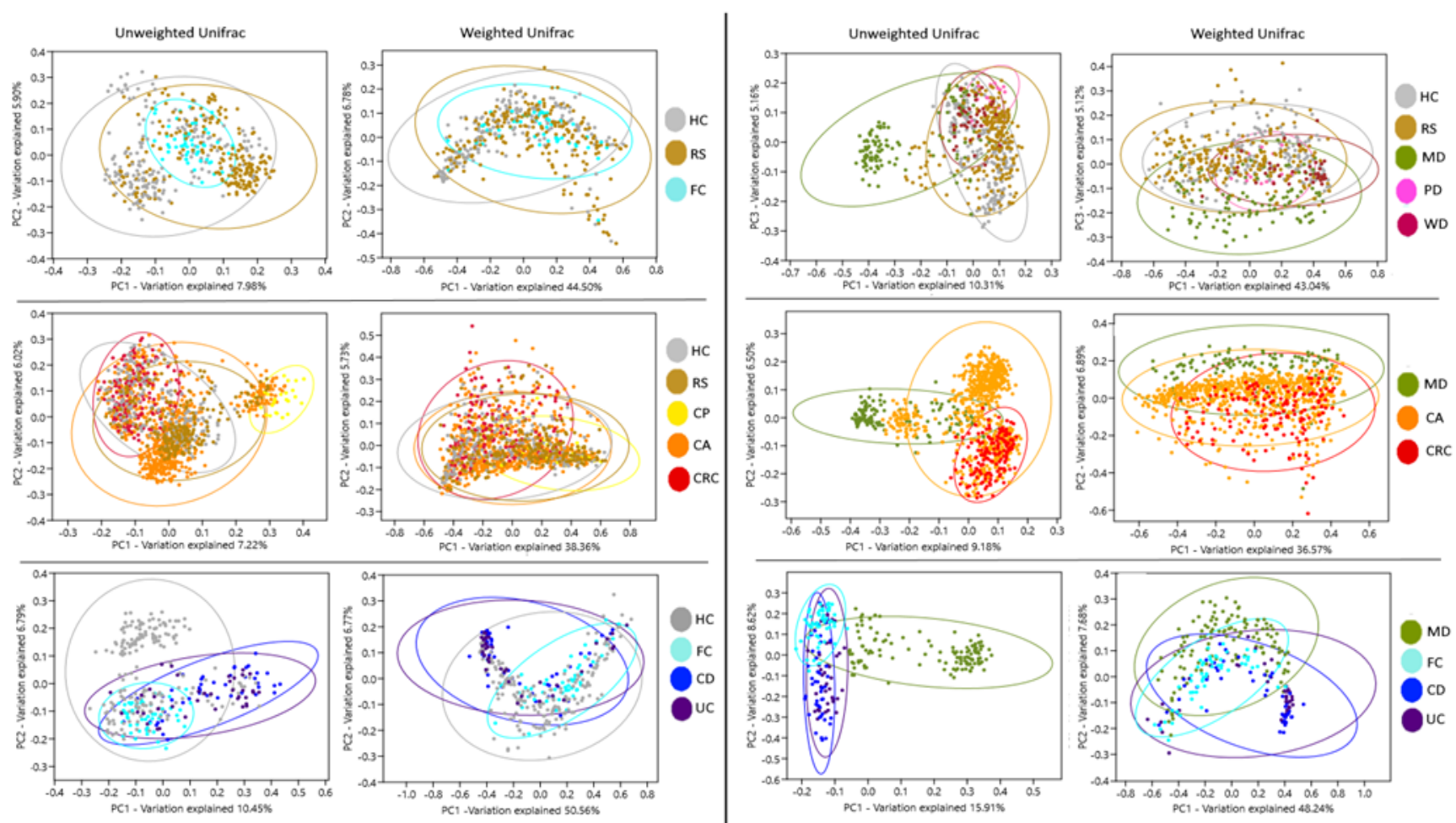

Figure 1. Analysis of bacteria community components. Principal coordinates analysis of Unifrac distances for the different groups. Ellipses indicate 95\% confidence intervals. Groups: Healthy subjects (HC), subjects at risk of developing colorectal cancer (RS), healthy familiars of IBD patients (FC). Patients with colon polyps (CP), colon adenoma (CA), colorectal cancer (CRC), Crohn's disease (CD), and ulcerative colitis (UC). Subjects following a Mediterranean (MD), modern Paleolithic (PD), or Western-like diet (WD).

Table 2. Average OTU composition (\%) of the different groups at phylum level.

\begin{tabular}{ccccccccccc}
\hline Phylum $^{1}$ & HC & RS & FC & MD & PD & WD & CP & CA & CRC & IBD \\
\hline Firmicutes & 58.9506 & 52.9856 & 50.5467 & 60.7094 & 62.6186 & 68.4219 & 43.9497 & 60.7098 & 57.1596 & 57.2953 \\
Bacteroidetes & 27.2735 & 33.3556 & 44.5428 & 23.4625 & 27.3412 & 15.0817 & 50.2231 & 27.0028 & 23.5202 & 30.5508 \\
Proteobacteria & 3.4721 & 4.7896 & 1.1461 & 3.3301 & 4.4188 & 1.6484 & 3.8428 & 6.5936 & 9.7906 & 3.8073 \\
Actinobacteria & 6.5486 & 5.6996 & 1.7042 & 8.7902 & 3.6509 & 11.9093 & 0.6523 & 1.2800 & 1.1112 & 6.7657 \\
Verrucomicrobia & 2.6702 & 2.5748 & 1.2910 & 3.1041 & 1.4947 & 0.9764 & 0.0091 & 2.5214 & 3.9575 & 0.8956 \\
Euryarchaeota & 0.5848 & 0.2252 & 0.2990 & 0.0847 & 0.0536 & 0.4117 & 0 & 1.0877 & 1.7885 & 0.0168 \\
Fusobacteria & 0.0146 & 0.0197 & 0.0029 & 0.0025 & 0.0042 & 0.0848 & 0.0117 & 0.2145 & 2.0454 & 0.2526 \\
Tenericutes & 0.3459 & 0.1043 & 0.3512 & 0.0482 & 0.2094 & 0.7785 & 0.0971 & 0.3692 & 0.2732 & 0.0329 \\
Cyanobacteria & 0.0581 & 0.1052 & 0.1002 & 0.2465 & 0.1488 & 0.2541 & 0.0536 & 0.0625 & 0.0579 & 0.0284 \\
Synergistetes & 0.0098 & 0.0513 & 0.0014 & 0.0441 & 0.007 & 0.0041 & 0.4129 & 0.0848 & 0.1576 & 0.0005 \\
Chloroflexi & 0.0024 & 0.0342 & 0.0008 & 0.0047 & 0 & 0.0179 & 0.4694 & 0.03 & 0.0011 & 0.0007 \\
TM7 & 0.0083 & 0.0191 & 0.0055 & 0.0653 & 0.007 & 0.0039 & 0.0013 & 0.0033 & 0.0014 & 0.0210 \\
\hline
\end{tabular}

Groups: Healthy subjects (HC), subjects at risk of developing colorectal cancer (RS), and healthy familiars of IBD patients (FC), Subjects following a Mediterranean (MD), modern Paleolithic (PD) or Western-like diet (WD). Patients with colon polyps (CP), colon adenoma (CA), colorectal cancer (CRC), and inflammatory bowel diseases (IBD). ${ }^{1}$ Phyla with an average relative abundance $>0.01 \%$. 

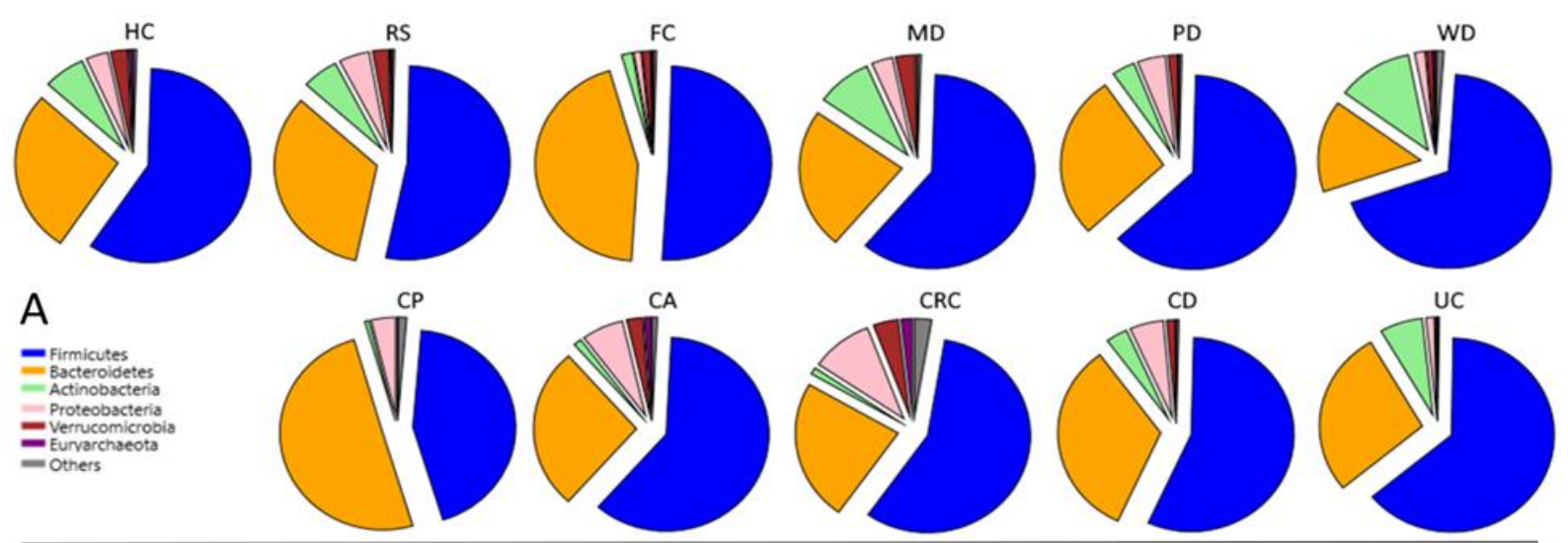

$C D$
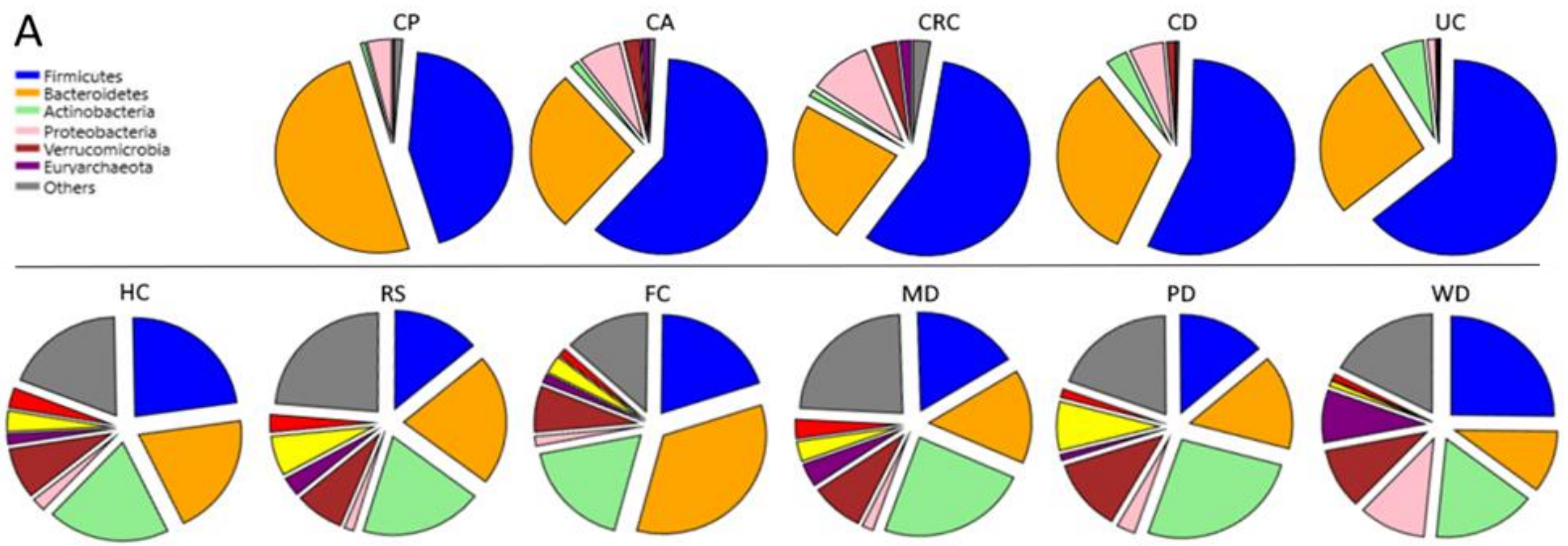

WD
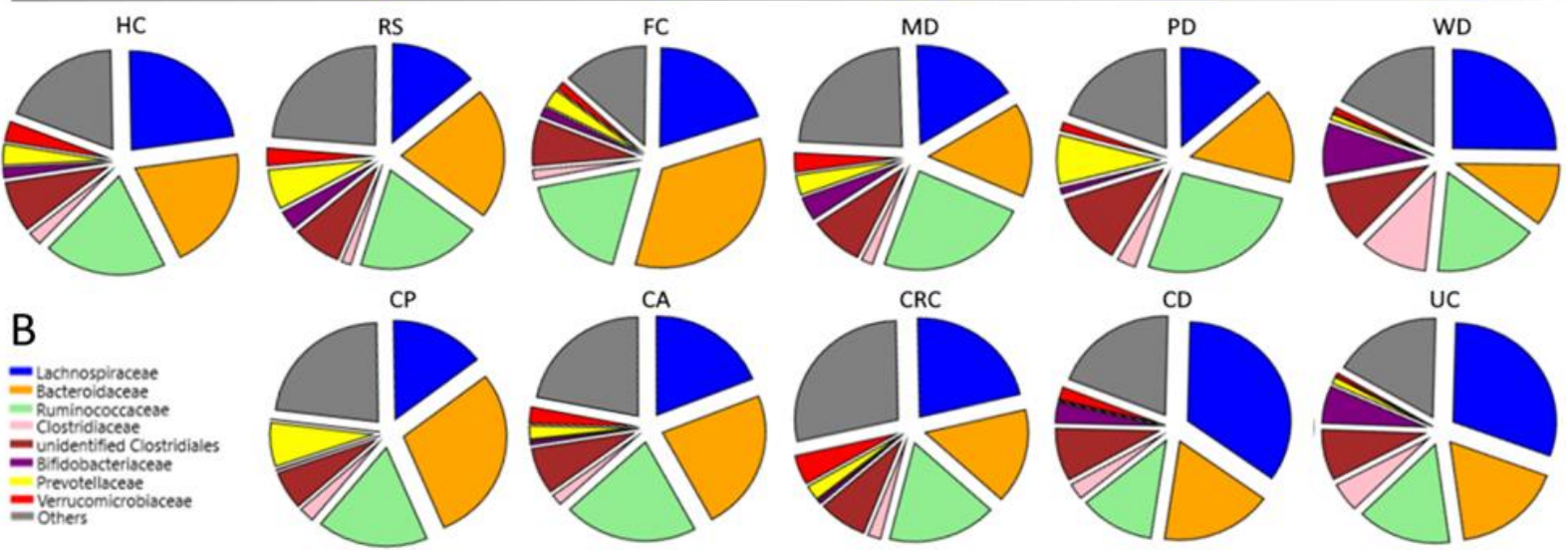

UC

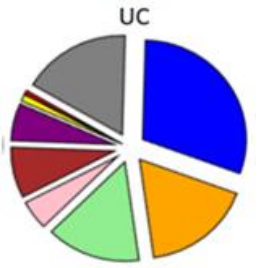

Figure 2. Microbiota composition of the different groups. Relative abundance of the most represented (A) phyla and (B) families. Groups: Healthy subjects (HC), subjects at risk of developing colorectal cancer (RS), healthy familiars of IBD patients (FC). Subjects following a Mediterranean (MD), modern Paleolithic (PD), or Western-like diet (WD). Patients with colon polyps (CP), colon adenoma (CA), colorectal cancer (CRC), Crohn's disease (CD), and ulcerative colitis patients (UC).

Table 3. Average OTU composition (\%) of the different groups at family level.

\begin{tabular}{ccccccccccc}
\hline Family $^{\mathbf{1}}$ & HC & RS & FC & MD & PD & WD & CP & CA & CRC & IBD \\
\hline Bacteroidaceae & 20.0833 & 21.4943 & 34.1572 & 15.4143 & 15.5215 & 10.1769 & 28.9815 & 23.0839 & 15.5119 & 17.7059 \\
Ruminococcaceae & 19.1884 & 19.3032 & 17.7934 & 23.7961 & 26.1617 & 15.8293 & 17.3777 & 21.0300 & 17.0954 & 12.9261 \\
Lachnospiraceae & 23.0466 & 13.8709 & 19.8088 & 16.7415 & 13.7672 & 25.2004 & 14.8706 & 19.0354 & 21.5969 & 32.3826 \\
Prevotellaceae & 3.4126 & 6.4874 & 2.9435 & 3.3205 & 7.9948 & 0.9122 & 7.1719 & 2.1619 & 2.4454 & 0.5454 \\
Verrucomicrobiaceae & 2.5702 & 2.5748 & 1.3390 & 3.1041 & 1.4059 & 1.0218 & 0.0091 & 2.6860 & 4.7985 & 1.4723 \\
Enterobacteriaceae & 1.8800 & 2.3051 & 0.1756 & 1.4505 & 1.5145 & 0.9643 & 2.8031 & 3.1807 & 4.6496 & 2.8912 \\
Rikenellaceae & 1.2078 & 2.3913 & 3.3995 & 0.9956 & 0.6892 & 1.3703 & 1.5607 & 3.7645 & 1.3509 & 1.4844 \\
Veillonellaceae & 1.3149 & 2.6069 & 1.5675 & 3.3201 & 3.1355 & 0.9408 & 1.4446 & 2.0480 & 3.2348 & 3.0156 \\
Erysipelotrichaceae & 1.3873 & 2.9033 & 1.6074 & 3.5306 & 2.7406 & 3.0238 & 2.0810 & 2.1707 & 1.2688 & 1.9607 \\
Clostridiaceae & 2.1895 & 1.5247 & 1.5840 & 1.8002 & 2.9558 & 10.5602 & 2.4377 & 1.8124 & 2.0468 & 3.6841 \\
Bifidobacteriaceae & 2.4882 & 3.0881 & 1.4775 & 3.8193 & 0.9905 & 8.5908 & 0.1076 & 0.7255 & 0.6851 & 4.1287 \\
Porphyromonadaceae & 1.4686 & 1.9259 & 2.1814 & 1.3922 & 0.6344 & 0.5258 & 1.9845 & 2.1017 & 2.6539 & 0.7964 \\
Coriobacteriaceae & 2.2984 & 2.8772 & 0.1868 & 4.8781 & 2.4784 & 3.3779 & 0.3076 & 0.4466 & 0.5358 & 3.5795 \\
Streptococcaceae & 0.7604 & 1.1587 & 0.1391 & 1.1514 & 1.6407 & 1.5708 & 0.8787 & 0.8000 & 1.3647 & 2.4764 \\
[Barnesiellaceae] & 0.8793 & 1.0808 & 0.7642 & 0.4972 & 0.5040 & 0.4677 & 0.4404 & 0.8730 & 0.4621 & 0.1233 \\
[Paraprevotellaceae] & 0.4943 & 0.8159 & 0.3284 & 0.8542 & 0.8998 & 0.6662 & 3.1720 & 0.7737 & 0.6244 & 0.0257 \\
S24-7 & 0.6452 & 0.8367 & 0.4641 & 0.5315 & 0.2762 & 0.3106 & 0.6800 & 0.5968 & 0.9590 & 0.1841 \\
Methanobacteriaceae & 0.6146 & 0.2509 & 0.2882 & 0.0847 & 0.0512 & 0.4403 & 0 & 0.6862 & 1.5798 & 0.0292 \\
Alcaligenaceae & 0.6979 & 0.8799 & 0.5232 & 0.2415 & 0.6768 & 0.2323 & 0.1827 & 0.2702 & 0.2863 & 0.3770 \\
\hline
\end{tabular}


Table 3. Cont.

\begin{tabular}{ccccccccccc}
\hline Family $^{1}$ & HC & RS & FC & MD & PD & WD & CP & CA & CRC & IBD \\
\hline [Odoribacteraceae] & 0.5183 & 0.2700 & 0.1939 & 0.2048 & 0.3140 & 0.2704 & 0.1536 & 0.2848 & 0.3808 & 0.0449 \\
Desulfovibrionaceae & 0.2213 & 0.4774 & 0.1547 & 0.2684 & 0.2958 & 0.1048 & 0.1304 & 0.2288 & 0.3753 & 0.1004 \\
Peptostreptococcaceae & 0.2905 & 0.3369 & 0.0330 & 0.3157 & 0.2815 & 0.2195 & 0.5588 & 0.1831 & 0.4749 & 0.5393 \\
Christensenellaceae & 0.2410 & 0.1657 & 0.2954 & 0.1624 & 0.5880 & 0.0704 & 0.1304 & 0.2189 & 0.7917 & 0.0163 \\
Sphingomonadaceae & 0.0051 & 0.0001 & 0.0001 & 0.0007 & 0 & 0.1645 & 0.0001 & 0.3026 & 1.3384 & 0.0001 \\
Lactobacillaceae & 0.2327 & 0.0474 & 0.0032 & 0.3848 & 0.0170 & 0.1321 & 0.3623 & 0.1945 & 0.3568 & 0.4582 \\
Fusobacteriaceae & 0.0173 & 0.0191 & 0.0035 & 0.0020 & 0.0040 & 0.0519 & 0.0030 & 0.2023 & 1.1520 & 0.2526 \\
\hline
\end{tabular}

Groups: Healthy subjects (HC), subjects at risk of developing colorectal cancer (RS), and healthy familiars of IBD patients (FC), Subjects following a Mediterranean (MD), modern Paleolithic (PD), or Western-like diet (WD). Patients with colon polyps (CP), colon adenoma (CA), colorectal cancer (CRC), and inflammatory bowel diseases (IBD). ${ }^{1}$ Families with an average relative abundance $>0.01 \%$.

Comparison between groups showed that MD-induced microbiota is different from that of the other diets, the controls without a defined dietary pattern (HC), and the RS group (Tables 2 and 3, Figure 2).

Out of the 12 most abundant phyla, nine were differently represented in MD compared to WD and four were differently represented in MD compared to PD (Table S5). The high data variability of the PD group reduced the significance of its differences with other groups. Still, MD differed from both PD and WD by an increase in Verrucomicrobia $\left(p=0.0099\right.$ and $p=5.6 \times 10^{-6}$ respectively), and from WD alone by a higher representation of Bacteroidetes $\left(p=7.9 \times 10^{-7}\right)$ and lower Firmicutes $(p=0.0002)$, Euryarchaeota $(p=0.0003)$ and Fusobacteria $\left(p=2.4 \times 10^{-10}\right)$, among other phyla. MD also presented nine differently represented phyla to RS and FC, and seven to HC, including a lower representation of Fusobacteria ( $p=0.0027, p=0.0051$ and $p=0.0002$ respectively) and higher of Verrucomicrobia and Actinobacteria ( $p<0.0001$ for all).

Among diseases, the CRC group distinguished from CA and CP by a higher presence of Proteobacteria, Fusobacteria, Euryarchaeota, and Verrucomicrobia $(p<0.0001$ for all $)$. The representation of these phyla was also higher in CRC than in HC (Proteobacteria $p=0.005$, Fusobacteria $p=0.0051$, Euryarchaeota $p=0.005$ and Verrucomicrobia $p=0.0082$ ), RS $(p<0.0001$ for all). Chronic inflammation-related UC and CD did not present statistically significant differences between them at any taxonomic level (Tables S5-S7); therefore, the two groups were merged for further comparison (IBD group). The IBD group presented seven differently represented phyla than $\mathrm{HC}$ among the 12 most abundant, but only three to FC, with a higher proportion of Firmicutes ( $p=0.0002$ and $p=2.5 \times 10^{-5}$ respectively) and Actinobacteria $(p=0.002$ and $p=0.0006)$ against both, and also higher Fusobacteria $(p=0.002)$ and lower Verrucomicrobia $(p=0.0002)$ compared to HC alone. The number of differentially represented phyla among the 12 most abundant in MD compared to CA and CRC was nine and ten respectively, with MD presenting higher Actinobacteria and lower Proteobacteria and Fusobacteria compared to both $(p<0.0001$ for all). Differently, MD showed a higher proportion of Verrucomicrobia than CA $\left(p=3.5 \times 10^{-14}\right)$ but lower than CRC $\left(p=7.3 \times 10^{-22}\right)$. Likewise, compared to IBD, MD had nine differentially represented phyla, including a higher proportion of Actinobacteria $(p=0.0001)$ and Verrucomicrobia $\left(p=4.9 \times 10^{-5}\right)$, and lower of Proteobacteria $(p=0.0003)$ and Fusobacteria $\left(p=2.6 \times 10^{-12}\right)$.

Some of the phyla described showed progressive increases or decreases in their relative abundance from subjects in the healthy, at-risk, and cancer-related groups, placing MD furthest from CRC (Figure 3).

The differences observed in some phyla were also present at genus levels. Actinobacteria phylum is composed by several genera differently represented between groups, being the most abundant Bifidobacterium, Collinsella, Adlercreutzia, and a non-annotated OTU within family Coriobacteriace (Figure 4). Adlercreutzia was higher in MD with respect to HC, RS, CA, CRC, and IBD $(p=0.0011, p=0.0024, p=0.0003, p=0.0002$ and $p=0.007$, respectively), while Collinsella was increased in IBD compared to HC, FC, and $\mathrm{MD}\left(p=1.3 \times 10^{-6}\right.$, $p=0.0074$ and $p=0.0086$, respectively). Finally, Bifidobacterium was decreased in CRC compared to HC, RS, and MD ( $p=0.0005, p=2.5 \times 10^{-5}$ and $p=1.5 \times 10^{-18}$, respectively). 

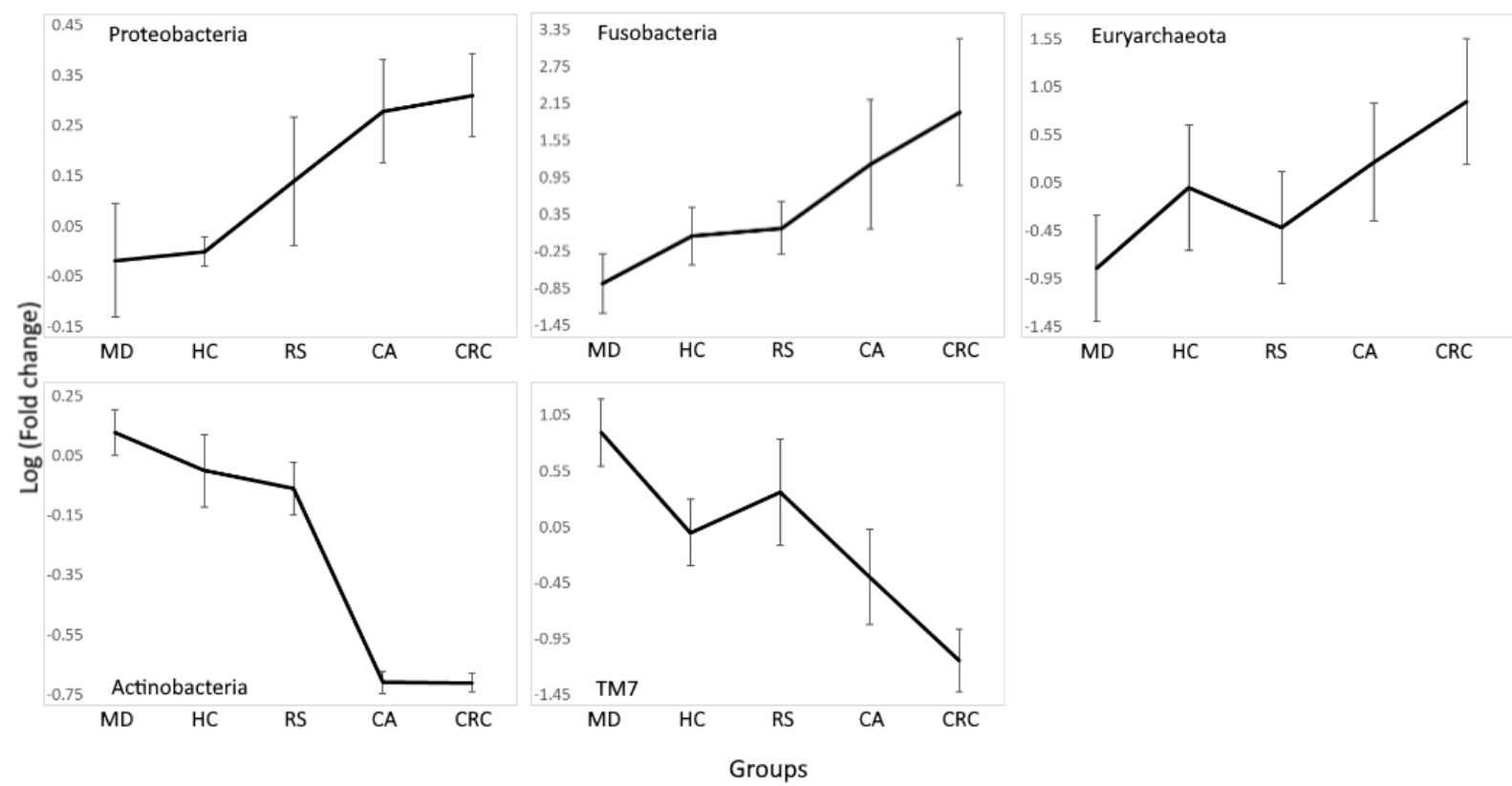

Figure 3. Phyla progressively increased or decreased from subjects in the Mediterranean diet (MD), healthy subjects (HC), subjects at risk of developing colorectal cancer (RS), colon adenoma (CA), and colorectal cancer patients (CRC) groups. Mean $\log _{10}$ fold change was calculated using the relative abundance in the HC group as a reference. Significant differences between MD and HC, HC and RS, RS and CA, and CA and CRC (FDR < 0.01) were found for all phyla except for CA and CRC comparison in TM7 (FDR = 0.96) (Table S5). Euryarchaeota and TM7 presented changes in relative abundance between $\mathrm{HC}$ and RS that do not follow the general trend; however, CA was increased in the former phyla and decreased in the latter when compared to both HC and RS.

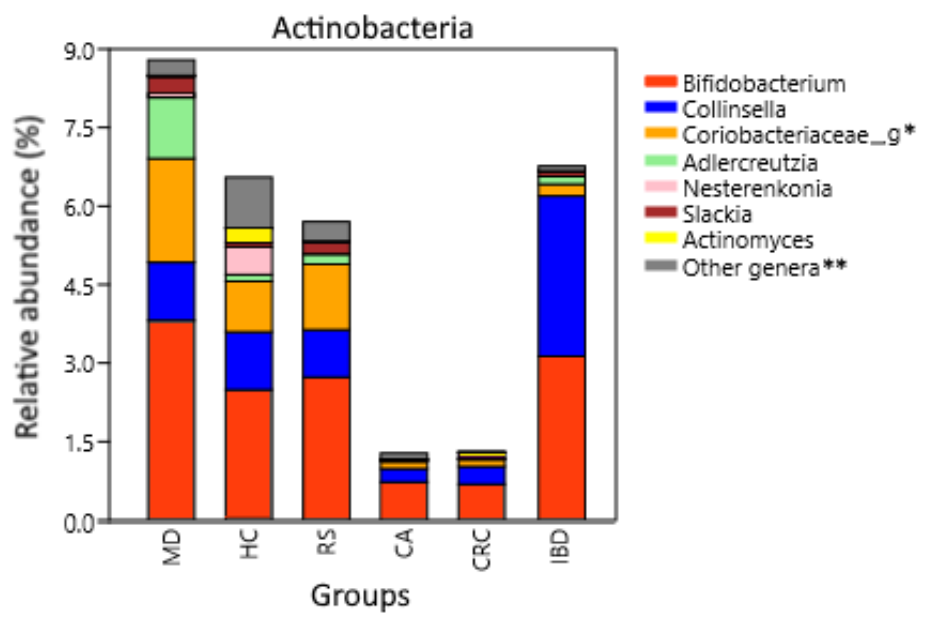

Figure 4. Actinobacteria composition at the genus level. Relative abundance corresponds to the average percentual fraction of reads in the group representing each OTU. Groups: Subjects following a Mediterranean diet (MD), healthy subjects (HC), subjects at risk of developing colorectal cancer (RS). Patients with colon adenoma (CA), colorectal cancer (CRC), or inflammatory bowel diseases (IBD). * Genus or genera unannotated in the reference database. ${ }^{* *}$ Less abundant genera and sequences that could not be classified at the genus level.

Analysis of genera also showed differences between groups that were not evident at the family level. The [Ruminococcus] genus from Lachnospiraceae was less represented in MD compared to HC $\left(p=3.6 \times 10^{-21}\right)$, FC $\left(p=1.5 \times 10^{-9}\right)$, and RS $\left(p=1.2 \times 10^{-7}\right)$, while it was increased in both IBD $(p=0.0097)$ and CRC $\left(p=4.4 \times 10^{-5}\right)$ against HC. Veillonellaceae 
is mainly constituted by the genera Dialister, Veillonella, and Phascolarctobacterium, which were the most abundant in MD, IBD, and CRC respectively (Figure 5).
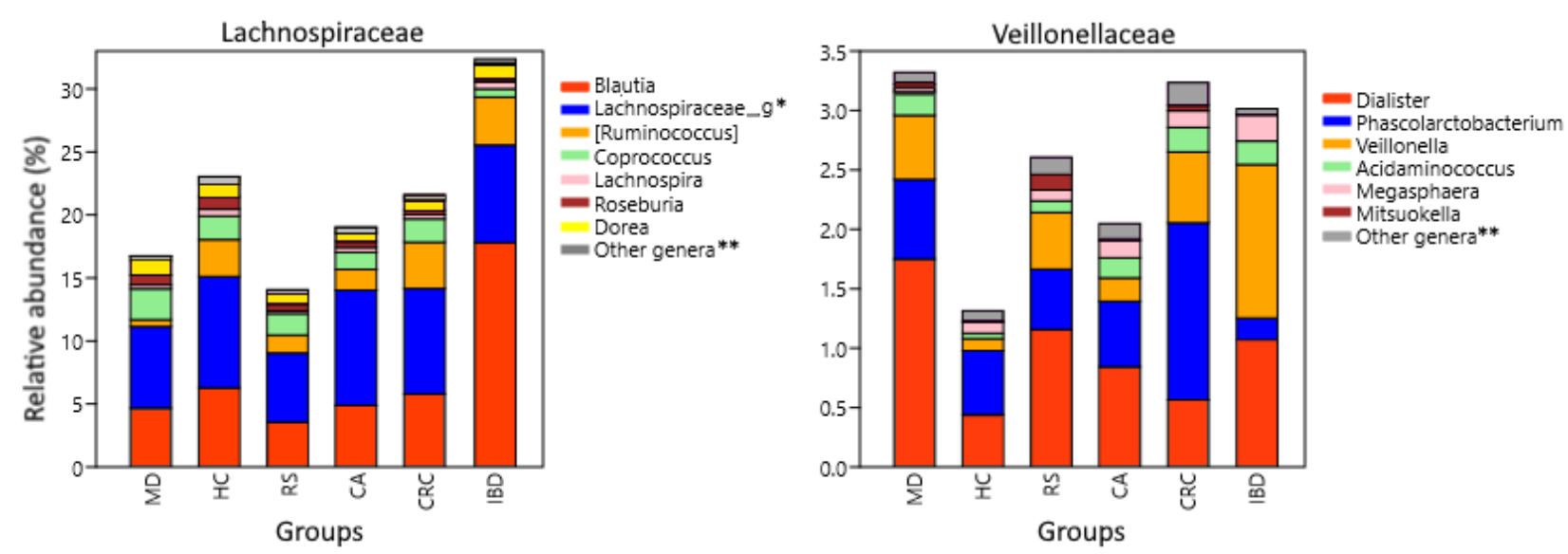

Figure 5. Lachnospiraceae and Veillonellaceae composition at genus level. Relative abundance corresponds to the average percentual fraction of reads in the group representing each OTU. Groups: Subjects following a Mediterranean diet (MD), healthy subjects (HC), subjects at risk of developing colorectal cancer (RS). Patients with colon adenoma (CA), colorectal cancer (CRC), or inflammatory bowel diseases (IBD). * Genus or genera unannotated in the reference database. ${ }^{* *}$ Less abundant genera and sequences that could not be classified at the genus level.

Other phyla such as Verrucomicrobia, Euryarchaeota, and Fusobacteria were prevalently constituted by a single genus: Akkermansia, Methanobrevibacter, and Fusobacterium, respectively (Tables S5-S7).

\section{Discussion}

The Mediterranean diet is widely accepted as part of a healthy lifestyle. Several studies, including those from our meta-analysis, show that the microbiota of MD subjects is enriched in bacteria with beneficial properties that help in maintaining gut barrier function and reducing inflammation. Instead, pathogenic bacteria with pro-inflammatory properties, which can impair the epithelial barrier function and produce toxic metabolites, are poorly represented. The gut microbiota of IBD, adenoma, and CRC shows an unbalanced bacterial composition that contributes to disease progression. We investigated if the bacterial population induced by MD may have preventive properties against these diseases.

Beta diversity analysis confirmed that microbiota associated to MD was different from that of the disease and control groups, and this was not observed with the other diets. Analysis of differently represented OTUs between groups found bacteria with a tendency to increase or decrease along an axis formed by MD-HC-RS-CA-CRC groups. In agreement with the hypothesis of microbiota components accompanying the formation of adenomas and the development of CRC, phyla with pro-inflammatory properties such as Proteobacteria and Euryarchaeota increased along the axis. A similar trend was also observed for Fusobacteria, which are known to promote colorectal carcinogenesis. In contrast, Actinobacteria, which include SCFA producers with anti-inflammatory properties, decreased (Figure 3).

The limited number of studies available on PD, WD, and CP resulted in the high variability and lack of statistical significance on these groups, and they did not consistently fit the axis. No statistical difference was found between PD and HC at the phylum level. Instead, WD presented a high variability and may be considered part of the axis in some cases, such as Fusobacteria, but not in others, such as Actinobacteria (Table S5). CP was found many times at similar levels to HC and RS, for example, in Proteobacteria and Fusobacteria. The IBD group, made up of subjects obtained from three different studies, had characteristics that could be considered intermediate between HC and CRC, because 
in most cases, it presented abundance levels similar to the first, as in Actinobacteria, or to the latter, as in Fusobacteria.

The Proteobacteria phylum is a marker of gut dysbiosis [68], and one of the phyla increased along the axis. It has been associated with a high-fat diet and obesity in mice [69], with consumption of animal fat [70], and most importantly, with a colonic mucosa more easily penetrated by other bacteria [71]. This may explain the low abundance observed in $\mathrm{MD}$, where animal fat consumption is greatly diminished, but not in PD, which includes several animal-derived products. Still, Proteobacteria is the most differently represented phyla between MD and PD $\left(p=8 \times 10^{-5}\right)$ and coincidently also between MD and HC $\left(p=2.6 \times 10^{-20}\right)$ (Table S5). The decrease of Proteobacteria in PD compared to HC was not significant $(p=1)$. The increasing trend along the axis is found further down at the family level, driven by Enterobacteriaceae, whose enrichment in the gut is favored by inflammation [72]. This family has previously been found increased in patients with CRC and IBD [73,74] and is a proposed marker of epithelial dysfunction [75]. Other families within Proteobacteria are also decreased in MD compared to controls and diseases, including Sphingomonadaceae and Helicobacteraceae. Sphingomonadaceae's most abundant genus, Sphingomonas, was found increased in IBD patients and is associated with CD recurrence [76,77], and it increased in colitis-associated CRC patients as well [78]. The Helicobacteraceae family includes the pathogen Helicobacter pylori, whose prevalence is increased in patients with gastric cancer [79]. This bacterium promotes its pathogenesis by inducing chronic inflammation, accumulation of mutations, and aberrant DNA methylation in the gastric mucosa through the expression of different virulence factors [80-82]. It is also found increased in CA and CRC patients [83], and its participation in CRC development has been suggested $[84,85]$.

The most abundant Fusobacteria species, Fusobacterium nucleatum, is a pathogen increased in IBD and CRC [86-88]. Fusobacterium suppresses the immune cell response in the gut while also promoting a pro-inflammatory and tumorigenic environment. It produces the virulence factor FadA, which is capable of binding E-cadherin and activating betacatenin [89], and Fap2, which can inhibit NK and T cell activity [90]. It also recruits several tumor-promoting cells, such as myeloid-derived suppressor cells and tumor-associated neutrophils and macrophages [91]. F. nucleatum promotes the destruction of the mucosal barrier by activating the endoplasmic reticulum stress pathway [92], and it has been associated with accelerated DNA methylation in the mucosa of UC patients [93]. The low abundance of Fusobacterium in MD may be associated with augmented dietary fiber and reduced fat consumption, as reported by studies on similar dietary patterns [94,95]. The reduction in abundance of a pathogen with such a significant role in cancer is indicative of the potential preventive function of the MD diet. Fusobacteria was also the most significant differently represented phylum between MD and WD $\left(p=2.4 \times 10^{-10}\right)$, and its greater representation in the latter when compared to HC may be indicative of a dietary adverse effect.

The only archaea phylum in the meta-analysis, Euryarchaeota, also increased along the MD-HC-RS-CA-CRC axis, except for RS (Figure 3). Euryarchaeota's main component, Methanobrevibacter smithii, is the dominant archaea species in the human gut, and its abundance correlates with the activation of several pro-inflammatory pathways in multiple sclerosis [96]. It is increased in CA and CRC patients [97] and decreased in obese individuals [98], which may explain the reduction observed in RS, which is a group defined by obesity and other commonly related clinical markers. According to the literature, Methanobrevibacter presented a low abundance in MD subjects [99]. The presence of Methanobrevibacter has been associated with the consumption of dietary fiber [100], but dairy products, which are consumed with moderation in MD, are also possible sources of M. smithii [101]. A similar low representation was found for PD, although the decrease was non-significant compared to HC.

An abundance of Actinobacteria has been associated with the consumption of dietary fiber and production of SCFAs [102,103]. These anti-inflammatory compounds are a source 
of energy for epithelial cells and help maintain the stability of the gut barrier [28,104]. Bifidobacterium and Adlercreutzia, two commensals with anti-inflammatory properties that are used as probiotics $[105,106]$, were the most abundant Actinobacteria genera in MD (Figure 4). The most common Adlercreutzia species is A. equolifasciens, which can produce the anti-inflammatory molecule equol $[106,107]$. Equol-producing microbiota is found in $59 \%$ of vegetarians compared to $25 \%$ in non-vegetarians [108]. The increase in vegetables consumption, together with the inclusion of omega 3-rich fat, which has also been related to an increase in Adlercreutzia [109], may explain its abundance in MD. We also found an increase of Actinobacteria in IBD subjects compared to FC and HC, confirming previous reports [110], but the increase was driven by the genera Bifidobacterium and Collinsella, and not by Adlercreutzia (Figure 4). Both Collinsella and Adlercreutzia are found in the Coriobacteriaceae family, but the bile-tolerant Collinsella has been linked to pro-inflammatory diseases, obesity, and low fiber consumption [111-113]. Another Actinobacteria genus increased in MD was Slackia, which was previously found increased after an intervention with a modified Mediterranean-ketogenic diet [114], and it includes species such as S. equolifasciens and S. isoflavoniconvertens, which are capable of producing equol $[115,116]$ but also the opportunistic S. exigua [117]. Actinobacteria phylum was found to be increased in the WD group compared to HC and PD, and indeed, this was the most differently represented phylum between PD and WD, but the increase was not significant compared to MD. At the genus level, WD had the second highest abundance of Collinsella, higher than MD, HC, and even RS, and only below that of the IBD group.

Another phylum that decreased along the MD-HC-RS-CA-CRC axis is TM7, which is currently known as candidatus Saccharibacteria, as it seems to consume mainly sugars [118], but studies on its potential role and activity are scarce. They are obligate epibionts/parasites of other bacteria, and their increase has been reported in the context of IBD [119], although the first successfully cultured strain repressed the expression of inflammatory TNF-alpha induced by its host [120]. Unfortunately, the lack of information on this phylum does not offer a possible explanation for its apparent increase in MD subjects.

The low fat and high dietary fiber content typical of MD foster an environment that favors the growth of anti-inflammatory bacteria and hinders that of pro-inflammatory and pathogenic bacteria. This is also evident when MD is compared to HC and highlights its beneficial effect on gut health.

Other phyla that did not follow the axis are also modulated by diet components typical of MD, but differences are observed at lower taxonomic levels. This was the case for families and genera within Firmicutes, including Ruminococcaceae, which had increased in MD and PD compared to all the other groups (Table 3). Several species of butyrateproducing bacteria are found within this family [121], and its abundance in MD and PD is most likely linked to the high consumption of dietary fiber, from which SCFAs are derived.

Two other Firmicutes families with both pro-inflammatory and anti-inflammatory components, Lachnospiraceae and Veillonellaceae, had differences at the genus level. Lachnospiraceae was lower in the MD group than in IBD and CRC (Figure 5). Regarding the genera included in this family, [Ruminoccocus], it was increased in IBD and CRC. These mucolytic bacteria have been found increased in IBD subjects, and one of its species, R. gnavus, synthesizes a pro-inflammatory polysaccharide [122-124]. Instead, butyrate producers with local anti-inflammatory effect, belonging to Roseburia, are depleted in both IBD and CRC [125-127]. MD and also PD were enriched in genera with anti-inflammatory properties, including Coprococcus, which can produce indole-propionic acid, which is a tryptophan-derived metabolite with antimycobacterial, antioxidant, and anti-inflammatory activities [128,129]. Furthermore, Dorea was increased in MD, while PD was enriched in Lachnospira. Both genera include some SCFA-producing pectin fermenters and are associated with vegetarian and vegan diets [130-132], but they have also been reported to increase in obese subjects $[133,134]$. Blautia is a butyrate producer inversely related to intestinal inflammation [135] but was nevertheless found increased in IBD. 
The family Veillonellaceae was increased in MD, CRC, and IBD compared to HC. The increase in MD was mainly driven by the genus Dialister, in CRC by Phascolarctobacterium, and in IBD by Veillonella (Figure 4). Bacteria belonging to these genera are capable of converting succinate and lactate into propionate [136-139]. Succinate and lactate are metabolites abundant in the tumor microenvironment, have pro-inflammatory properties, and participate in the activation of tumor-associated macrophages $[140,141]$. Lactate is also found increased in IBD patients and correlates with disease severity [142]. Dialister abundance is negatively correlated with total carbohydrates and starch ingestion [143] but is increased by the ingestion of dietary fiber $[144,145]$, which would explain the increase in MD. Importantly, a higher anti-inflammatory response driven by the inclusion of whole grains in the diet was observed in subjects with increased proportions of Dialister [145]. Phascolarctobacterium increased in CRC and decreased in IBD. Its abundance has been associated with lower circulating levels of inflammatory markers [146], and the decrease observed in IBD has already been reported in patients and linked to colon inflammation [147]. An increase in Phascolarctobacterium was reported in CRC patients, particularly early-stage patients [148,149], and interestingly, both succinate and lactate are overrepresented in their fecal metabolome [149]. Therefore, its increase in CRC may be related to the augmented succinate and lactate availability and not necessarily to the gut microbiota health or the local inflammation status. The genus Veillonella, which was increased in IBD (Figure 4), includes the species $V$. parvula, which expresses a lipopolysaccharide with pro-inflammatory activity [150] and induces strong expression of proinflammatory IL6 in vitro, inhibiting the expression of potentially antitumoral IL12p70 induced by other bacteria [151]. Veillonella was also increased and was positively correlated with pro-carcinogenic TMAO levels in IBD patients, and it was further increased in Crohn's patients with deep ulcers [152,153].

The less frequent Veillonellaceae genera Megasphaera, Acidaminococcus, and Mitsuokella are also SCFA producers [154-156]. They all use amino acids as a carbon source and have different affinities for them [157]. This observation could explain the different abundances observed, as vegetable sources (soy, rice), which are increased in MD, have less lysine but more histidine than animal sources (whey) [158]. For example, Megasphaera, which was low in the MD group, grows well in the presence of lysine but not of histidine [157].

Another taxon of interest is the phylum Verrucomicrobia, mainly composed of the genus Akkermansia, which we found increased in MD and decreased in IBD compared to RS, $\mathrm{HC}$, or FC, but also increased in CRC. The presence of this mucolytic bacterium is normally associated with a healthy microbiota [159] and inversely related to inflammation [160]. The increase observed in MD has not been reported before and may be related to the ingestion of fiber, which has been shown to increase mucin expression in animal models [161,162]. The decrease in Akkermansia abundance in IBD subjects and the increase in CRC had already been reported [122,148,163]. Its high abundance in cancer is probably associated with changes in mucins expression associated with CRC progression, including an upregulation of MUC5AC and downregulation of MUC2 [164], and even the loss of its expression in some patients [165]. Although a direct association between mucin types expression and mucolytic bacteria abundance has not been demonstrated, an increase of Akkermansia has been observed in $M u c 2^{-/-}$mice [166], and in the Winnie mice strain, which produces an aberrant MUC2 [167]. Conversely, Akkermansia is decreased in in vitro culture assays with MUC2 as the sole carbon source, while growth of [Ruminoccocus] species is favored [122].

For the phylum Bacteroidetes, we observed a decrease in the Prevotellaceae family and its main genus Prevotella, in IBD, CA, and CRC compared to HC and MD. The decrease of Prevotellaceae was previously reported in UC [168] and CRC patients [148]. Some species have pro-inflammatory properties, while others have anti-inflammatory ones [169,170]. No differences were found for Bacteroidaceae, which is another Bacteroidetes family. Bacteroidaceae are mainly composed of the genus Bacteroides and include both benefic and pathogenic species [171].

The observed differences between diets and patient groups suggest that MD may have a potentially beneficial effect on the patient's microbiota by increasing beneficial 
bacteria such as Akkermansia and Adlercreutzia or the Ruminococcaceae family, reducing at the same time potential pathogenic pro-inflammatory bacteria such as Fusobacterium or Proteobacteria. Despite the high variability of the data from WD and PD groups, few conclusions could be reached. However, some of the observed effects of WD in microbiota, such as the increases in Fusobacterium and Collinsella, suggest that this diet may be harmful to patient's health. For PD, we observed few differences that may be considered beneficial, mainly increases in Ruminococaceae, Coprococcus, and Lachnospira. However, these changes alone could hardly suggest a potential benefit or harm. In all cases, further testing would be needed to confirm their potential therapeutic or harmful effect on patients.

Our study presented some limitations stemming from the limited availability of highquality $16 \mathrm{~S}$ public data for certain diets or diseases, which made it difficult to balance the number of subjects in each group, as well as their gender or age. This also led us to choose to not perform analyses below the genus, due to the greater number of unidentified OTUs at the species level compared to all other taxonomic levels. Furthermore, the data used have provided us with valuable information on the bacterial composition but do not allow evaluating their metabolic activity or evaluating other components of the microbiome such as fungi or viruses.

\section{Conclusions}

We conducted a meta-analysis of diets and intestinal diseases related to inflammation and cancer that highlights unique characteristics of the bacterial population associated with MD. The microbiota of subjects following MD was enriched with beneficial bacteria that promote an anti-inflammatory environment, which were instead reduced in IBD, CA, and CRC groups. Conversely, taxa with pro-inflammatory properties that can alter the gut barrier functions were reduced in MD and increased in IBD, CA, and CRC groups. Among the modulated taxa, we reported for the first time an increase in Akkermansia and a reduction in Fusobacterium in MD, even below the levels observed in healthy subjects without a defined diet. Akkermansia is a marker of a healthy gut, and Fusobacterium is a known pathogenic bacterium associated with cancer and IBD. Fusobacterium has also a critical role in mediating CRC chemoresistance to oxaliplatin and fluorouracil (5-FU) regimens by activating the autophagy pathway [172]. Our results suggest that MD's effect on the gut microbiota has the potential to prevent cancer and other inflammation-related diseases of the gut.

Supplementary Materials: The following are available online at https:/ /www.mdpi.com/article/10 $.3390 /$ nu13072234/s1, Figure S1: Alpha diversity comparison between diets, Figure S2: Alpha diversity comparison between diseases, Figure S3: Beta diversity principal coordinates (PCoA) analysis of diets, Figure S4: Beta diversity principal coordinates ( $\mathrm{PCoA})$ analysis of control groups, Figure S5: Beta diversity principal coordinates (PCoA) analysis of IBD groups, Figure S6: Beta diversity principal coordinates (PCoA) analysis of CRC-related groups, Table S1: Studies included in the metanalysis, Table S2: Inclusion criteria for the colorectal cancer risk group, Table S3: Alpha diversity comparison between groups with a non parametric $t$-test, Table S4: Significance of principal components data separation between groups, Table S5: Average OTU representation at the taxonomic phylum level and comparison between groups, Table S6: Average OTU representation at the taxonomic family level and comparison between groups, Table S7: Average OTU representation at the taxonomic genus level and comparison between groups, Table S8: Alpha diversity diet groups pairings comparisons, Table S9: Alpha diversity disease groups pairings comparisons.

Author Contributions: Conception and design O.I., M.R.-S. and M.G.; data acquisition and analysis O.I.; literature investigation and interpretation, O.I. and M.G.; writing-original draft preparation, O.I.; writing—review and editing, M.G. and M.R.-S.; supervision, M.G. All authors have read and agreed to the published version of the manuscript.

Funding: The European H2020 research project Oncobiome (Grant number 825410). Funds obtained through an Italian law that allows taxpayers to allocate $0.5 \%$ share of their income tax contribution to a research institution of their choice. O.I. was recipient of a postdoctoral fellowship from National Council of Science and Technology of Mexico (CONACYT). 
Institutional Review Board Statement: Not applicable.

Informed Consent Statement: Not applicable.

Data Availability Statement: The data presented in this study are openly available in the NCBI short reads archive (SRA), accessions PRJEB2165 [45], PRJNA318004 [55], PRJNA388210 [56], PRJNA450340 [57], PRJNA324147 [58], PRJEB39062 [59], PRJNA510080 [60], PRJNA534511 [61], PRJEB14782 [40], PRJNA247489 [62], PRJEB6070 [64], PRJNA516932 [65]; or in MG-RAST, project IDs mgp6248 [27], mgp80356 [46], mgp88216 [44], mgp89161 [41]; or in the Microbiome CRC Biomarker Study data file repository $[63,173]$.

Acknowledgments: Not applicable.

Conflicts of Interest: The authors declare no conflict of interest.

\section{References}

1. Kopp, W. How western diet and lifestyle drive the pandemic of obesity and civilization diseases. Diabetes Metab. Syndr. Obes. Targets Ther. 2019, 12, 2221. [CrossRef]

2. Ehlers, S.; Kaufmann, S.H. Infection, inflammation, and chronic diseases: Consequences of a modern lifestyle. Trends Immunol. 2010, 31, 184-190. [CrossRef] [PubMed]

3. Shi, Z. Gut Microbiota: An Important Link between Western Diet and Chronic Diseases. Nutrients 2019, $11,2287$.

4. Thorburn, A.N.; Macia, L.; Mackay, C.R. Diet, metabolites, and "western-lifestyle" inflammatory diseases. Immunity 2014, 40, 833-842. [CrossRef]

5. Karunanithi, S.; Levi, L. High-fat diet and colorectal cancer: Myths and facts. Future Med. 2018, 14. [CrossRef] [PubMed]

6. Molendijk, I.; van der Marel, S.; Maljaars, P. Towards a Food Pharmacy: Immunologic Modulation through Diet. Nutrients 2019, 11, 1239. [CrossRef] [PubMed]

7. Lucini, D.; Vigo, C.; Malacarne, M.; Gatzemeier, W.; Pagani, M. Lifestyle changes as internal medicine. Eur. J. Intern. Med. 2017, 43, 40-42. [CrossRef]

8. Stephenson, J.; Heslehurst, N.; Hall, J.; Schoenaker, D.A.; Hutchinson, J.; Cade, J.E.; Poston, L.; Barrett, G.; Crozier, S.R.; Barker, M. Before the beginning: Nutrition and lifestyle in the preconception period and its importance for future health. Lancet 2018, 391, 1830-1841. [CrossRef]

9. Willett, W.C.; Sacks, F.; Trichopoulou, A.; Drescher, G.; Ferro-Luzzi, A.; Helsing, E.; Trichopoulos, D. Mediterranean diet pyramid: A cultural model for healthy eating. Am. J. Clin. Nutr. 1995, 61, 1402S-1406S. [CrossRef] [PubMed]

10. Sanches Machado d'Almeida, K.; Ronchi Spillere, S.; Zuchinali, P.; Corrêa Souza, G. Mediterranean diet and other dietary patterns in primary prevention of heart failure and changes in cardiac function markers: A systematic review. Nutrients 2018, 10, 58. [CrossRef]

11. Di Daniele, N.; Noce, A.; Vidiri, M.F.; Moriconi, E.; Marrone, G.; Annicchiarico-Petruzzelli, M.; D’Urso, G.; Tesauro, M.; Rovella, V.; De Lorenzo, A. Impact of Mediterranean diet on metabolic syndrome, cancer and longevity. Oncotarget 2017, 8, 8947. [CrossRef] [PubMed]

12. Reddavide, R.; Rotolo, O.; Caruso, M.G.; Stasi, E.; Notarnicola, M.; Miraglia, C.; Nouvenne, A.; Meschi, T.; De'Angelis, G.L.; Di Mario, F. The role of diet in the prevention and treatment of Inflammatory Bowel Diseases. Acta Bio-Med. Atenei Parm. 2018, 89,60 .

13. Farinetti, A.; Zurlo, V.; Manenti, A.; Coppi, F.; Mattioli, A.V. Mediterranean diet and colorectal cancer: A systematic review. Nutrition 2017, 43, 83-88. [CrossRef] [PubMed]

14. Zazpe, I.; Martínez, J.A.; Santiago, S.; Carlos, S.; Zulet, M.Á.; Ruiz-Canela, M. Scoping review of Paleolithic dietary patterns: A definition proposal. Nutr. Res. Rev. 2020,34,1-29.

15. de Menezes, E.V.A.; de Carvalho Sampaio, H.A.; Carioca, A.A.F.; Parente, N.A.; Brito, F.O.; Moreira, T.M.M.; de Souza, A.C.C.; Arruda, S.P.M. Influence of Paleolithic diet on anthropometric markers in chronic diseases: Systematic review and meta-analysis. Nutr. J. 2019, 18, 41. [CrossRef]

16. Otten, J.; Stomby, A.; Waling, M.; Isaksson, A.; Tellström, A.; Lundin-Olsson, L.; Brage, S.; Ryberg, M.; Svensson, M.; Olsson, T. Benefits of a Paleolithic diet with and without supervised exercise on fat mass, insulin sensitivity, and glycemic control: A randomized controlled trial in individuals with type 2 diabetes. Diabetes/Metab. Res. Rev. 2017, 33, e2828. [CrossRef]

17. Ghaedi, E.; Mohammadi, M.; Mohammadi, H.; Ramezani-Jolfaie, N.; Malekzadeh, J.; Hosseinzadeh, M.; Salehi-Abargouei, A. Effects of a Paleolithic diet on cardiovascular disease risk factors: A systematic review and meta-analysis of randomized controlled trials. Adv. Nutr. 2019, 10, 634-646. [CrossRef]

18. Otten, J.; Mellberg, C.; Ryberg, M.; Sandberg, S.; Kullberg, J.; Lindahl, B.; Larsson, C.; Hauksson, J.; Olsson, T. Strong and persistent effect on liver fat with a Paleolithic diet during a two-year intervention. Int. J. Obes. 2016, 40, 747-753. [CrossRef]

19. Khan, S.; Waliullah, S.; Godfrey, V.; Khan, M.A.W.; Ramachandran, R.A.; Cantarel, B.L.; Behrendt, C.; Peng, L.; Hooper, L.V.; Zaki, H. Dietary simple sugars alter microbial ecology in the gut and promote colitis in mice. Sci. Transl. Med. 2020, 12, 567. [CrossRef]

20. Chassaing, B.; Van de Wiele, T.; De Bodt, J.; Marzorati, M.; Gewirtz, A.T. Dietary emulsifiers directly alter human microbiota composition and gene expression ex vivo potentiating intestinal inflammation. Gut 2017, 66, 1414-1427. [CrossRef] [PubMed] 
21. Suez, J.; Korem, T.; Zeevi, D.; Zilberman-Schapira, G.; Thaiss, C.A.; Maza, O.; Israeli, D.; Zmora, N.; Gilad, S.; Weinberger, A. Artificial sweeteners induce glucose intolerance by altering the gut microbiota. Nature 2014, 514, 181-186. [CrossRef]

22. Wan, Y.; Tong, W.; Zhou, R.; Li, J.; Yuan, J.; Wang, F.; Li, D. Habitual animal fat consumption in shaping gut microbiota and microbial metabolites. Food Funct. 2019, 10, 7973-7982. [CrossRef]

23. Genoni, A.; Christophersen, C.T.; Lo, J.; Coghlan, M.; Boyce, M.C.; Bird, A.R.; Lyons-Wall, P.; Devine, A. Long-term Paleolithic diet is associated with lower resistant starch intake, different gut microbiota composition and increased serum TMAO concentrations. Eur. J. Nutr. 2020, 59, 1845-1858. [CrossRef]

24. Zhu, Y.; Lin, X.; Zhao, F.; Shi, X.; Li, H.; Li, Y.; Zhu, W.; Xu, X.; Li, C.; Zhou, G. Meat, dairy and plant proteins alter bacterial composition of rat gut bacteria. Sci. Rep. 2015, 5, 15220. [CrossRef] [PubMed]

25. Koecher, K.J.; McKeown, N.M.; Sawicki, C.M.; Menon, R.S.; Slavin, J.L. Effect of whole-grain consumption on changes in fecal microbiota: A review of human intervention trials. Nutr. Rev. 2019, 77, 487-497. [CrossRef]

26. Fernando, W.; Hill, J.; Zello, G.; Tyler, R.; Dahl, W.; Van Kessel, A. Diets supplemented with chickpea or its main oligosaccharide component raffinose modify faecal microbial composition in healthy adults. Benef. Microbes 2010, 1, 197-207. [CrossRef] [PubMed]

27. David, L.A.; Maurice, C.F.; Carmody, R.N.; Gootenberg, D.B.; Button, J.E.; Wolfe, B.E.; Ling, A.V.; Devlin, A.S.; Varma, Y.; Fischbach, M.A. Diet rapidly and reproducibly alters the human gut microbiome. Nature 2014, 505, 559-563. [CrossRef] [PubMed]

28. Morrison, D.J.; Preston, T. Formation of short chain fatty acids by the gut microbiota and their impact on human metabolism. Gut Microbes 2016, 7, 189-200. [CrossRef]

29. Romano, K.A.; Vivas, E.I.; Amador-Noguez, D.; Rey, F.E. Intestinal microbiota composition modulates choline bioavailability from diet and accumulation of the proatherogenic metabolite trimethylamine-N-oxide. MBio 2015, 6, e02481-14. [CrossRef] [PubMed]

30. Sonnenburg, J.L.; Bäckhed, F. Diet-microbiota interactions as moderators of human metabolism. Nature 2016, 535, 56-64. [CrossRef] [PubMed]

31. Yap, Y.A.; Mariño, E. An insight into the intestinal web of mucosal immunity, microbiota, and diet in inflammation. Front. Immunol. 2018, 9, 2617. [CrossRef]

32. Telle-Hansen, V.H.; Holven, K.B.; Ulven, S.M. Impact of a healthy dietary pattern on gut microbiota and systemic inflammation in humans. Nutrients 2018, 10, 1783. [CrossRef] [PubMed]

33. Belizário, J.E.; Faintuch, J.; Garay-Malpartida, M. Gut microbiome dysbiosis and immunometabolism: New frontiers for treatment of metabolic diseases. Mediat. Inflamm. 2018, 2018. [CrossRef] [PubMed]

34. Grochowska, M.; Wojnar, M.; Radkowski, M. The gut microbiota in neuropsychiatric disorders. Acta Neurobiol. Exp. 2018, 78, 69-81. [CrossRef]

35. Zeng, M.; Inohara, N.; Nuñez, G. Mechanisms of inflammation-driven bacterial dysbiosis in the gut. Mucosal Immunol. 2017, 10, 18-26. [CrossRef] [PubMed]

36. Koliarakis, I.; Messaritakis, I.; Nikolouzakis, T.K.; Hamilos, G.; Souglakos, J.; Tsiaoussis, J. Oral bacteria and intestinal dysbiosis in colorectal cancer. Int. J. Mol. Sci. 2019, 20, 4146. [CrossRef]

37. Duboc, H.; Rajca, S.; Rainteau, D.; Benarous, D.; Maubert, M.-A.; Quervain, E.; Thomas, G.; Barbu, V.; Humbert, L.; Despras, G. Connecting dysbiosis, bile-acid dysmetabolism and gut inflammation in inflammatory bowel diseases. Gut 2013, 62, 531-539. [CrossRef]

38. Kaplan, G.G. The global burden of IBD: From 2015 to 2025. Nat. Rev. Gastroenterol. Hepatol. 2015, 12, 720-727. [CrossRef]

39. Arnold, M.; Sierra, M.S.; Laversanne, M.; Soerjomataram, I.; Jemal, A.; Bray, F. Global patterns and trends in colorectal cancer incidence and mortality. Gut 2017, 66, 683-691. [CrossRef]

40. PubMed. Available online: https://pubmed.ncbi.nlm.nih.gov (accessed on 15 August 2020).

41. Sequence Read Archive. Available online: https://www.ncbi.nlm.nih.gov/sra (accessed on 15 August 2020).

42. Vitaglione, P.; Mennella, I.; Ferracane, R.; Rivellese, A.A.; Giacco, R.; Ercolini, D.; Gibbons, S.M.; La Storia, A.; Gilbert, J.A.; Jonnalagadda, S. Whole-grain wheat consumption reduces inflammation in a randomized controlled trial on overweight and obese subjects with unhealthy dietary and lifestyle behaviors: Role of polyphenols bound to cereal dietary fiber. Am. J. Clin. Nutr. 2015, 101, 251-261. [CrossRef]

43. Barone, M.; Turroni, S.; Rampelli, S.; Soverini, M.; D’Amico, F.; Biagi, E.; Brigidi, P.; Troiani, E.; Candela, M. Gut microbiome response to a modern Paleolithic diet in a Western lifestyle context. PLoS ONE 2019, 14, e0220619. [CrossRef]

44. Sofi, F.; Dinu, M.; Pagliai, G.; Marcucci, R.; Casini, A. Validation of a literature-based adherence score to Mediterranean diet: The MEDI-LITE score. Int. J. Food Sci. Nutr. 2017, 68, 757-762. [CrossRef] [PubMed]

45. Agnoli, C.; Krogh, V.; Grioni, S.; Sieri, S.; Palli, D.; Masala, G.; Sacerdote, C.; Vineis, P.; Tumino, R.; Frasca, G. A priori-defined dietary patterns are associated with reduced risk of stroke in a large Italian cohort. J. Nutr. 2011, 141, 1552-1558. [CrossRef]

46. Hess, A.L.; Benítez-Páez, A.; Blædel, T.; Larsen, L.H.; Iglesias, J.R.; Madera, C.; Sanz, Y.; Larsen, T.M.; Consortium, M. The effect of inulin and resistant maltodextrin on weight loss during energy restriction: A randomised, placebo-controlled, double-blinded intervention. Eur. J. Nutr. 2020, 59, 2507-2524. [CrossRef]

47. Tap, J.; Furet, J.P.; Bensaada, M.; Philippe, C.; Roth, H.; Rabot, S.; Lakhdari, O.; Lombard, V.; Henrissat, B.; Corthier, G. Gut microbiota richness promotes its stability upon increased dietary fibre intake in healthy adults. Environ. Microbiol. 2015, 17, 4954-4964. [CrossRef] 
48. Hiel, S.; Bindels, L.B.; Pachikian, B.D.; Kalala, G.; Broers, V.; Zamariola, G.; Chang, B.P.; Kambashi, B.; Rodriguez, J.; Cani, P.D. Effects of a diet based on inulin-rich vegetables on gut health and nutritional behavior in healthy humans. Am. J. Clin. Nutr. 2019, 109, 1683-1695. [CrossRef]

49. Caporaso, J.G.; Kuczynski, J.; Stombaugh, J.; Bittinger, K.; Bushman, F.D.; Costello, E.K.; Fierer, N.; Pena, A.G.; Goodrich, J.K.; Gordon, J.I. QIIME allows analysis of high-throughput community sequencing data. Nat. Methods 2010, 7, 335-336. [CrossRef]

50. Bolger, A.M.; Lohse, M.; Usadel, B. Trimmomatic: A flexible trimmer for Illumina sequence data. Bioinformatics 2014, 30, 2114-2120. [CrossRef]

51. Edgar, R.C. Search and clustering orders of magnitude faster than BLAST. Bioinformatics 2010, 26, 2460-2461. [CrossRef]

52. Caporaso, J.G.; Bittinger, K.; Bushman, F.D.; DeSantis, T.Z.; Andersen, G.L.; Knight, R. PyNAST: A flexible tool for aligning sequences to a template alignment. Bioinformatics 2010, 26, 266-267. [CrossRef]

53. DeSantis, T.Z.; Hugenholtz, P.; Larsen, N.; Rojas, M.; Brodie, E.L.; Keller, K.; Huber, T.; Dalevi, D.; Hu, P.; Andersen, G.L. Greengenes, a chimera-checked 16S rRNA gene database and workbench compatible with ARB. Appl. Environ. Microbiol. 2006, 72, 5069-5072. [CrossRef]

54. Haas, B.J.; Gevers, D.; Earl, A.M.; Feldgarden, M.; Ward, D.V.; Giannoukos, G.; Ciulla, D.; Tabbaa, D.; Highlander, S.K.; Sodergren, E. Chimeric 16S rRNA sequence formation and detection in Sanger and 454-pyrosequenced PCR amplicons. Genome Res. 2011, 21, 494-504. [CrossRef] [PubMed]

55. Lozupone, C.; Knight, R. UniFrac: A new phylogenetic method for comparing microbial communities. Appl. Environ. Microbiol. 2005, 71, 8228-8235. [CrossRef]

56. Hammer, Ø.; Harper, D.A.; Ryan, P.D. PAST: Paleontological statistics software package for education and data analysis. Palaeontol. Electron. 2001, 4, 9.

57. Baxter, N.T.; Koumpouras, C.C.; Rogers, M.A.; Ruffin, M.T.; Schloss, P.D. DNA from fecal immunochemical test can replace stool for detection of colonic lesions using a microbiota-based model. Microbiome 2016, 4, 59. [CrossRef]

58. Jacob, V.; Crawford, C.; Cohen-Mekelburg, S.; Viladomiu, M.; Putzel, G.G.; Schneider, Y.; Chabouni, F.; O’Neil, S.; Bosworth, B.; Woo, V. Single delivery of high-diversity fecal microbiota preparation by colonoscopy is safe and effective in increasing microbial diversity in active ulcerative colitis. Inflamm. Bowel Dis. 2017, 23, 903-911. [CrossRef]

59. Forbes, J.D.; Chen, C.-Y.; Knox, N.C.; Marrie, R.-A.; El-Gabalawy, H.; de Kievit, T.; Alfa, M.; Bernstein, C.N.; Van Domselaar, G. A comparative study of the gut microbiota in immune-mediated inflammatory diseases-Does a common dysbiosis exist? Microbiome 2018, 6, 1-15. [CrossRef] [PubMed]

60. Jacobs, J.P.; Goudarzi, M.; Singh, N.; Tong, M.; McHardy, I.H.; Ruegger, P.; Asadourian, M.; Moon, B.-H.; Ayson, A.; Borneman, J. A disease-associated microbial and metabolomics state in relatives of pediatric inflammatory bowel disease patients. Cell. Mol. Gastroenterol. Hepatol. 2016, 2, 750-766. [CrossRef] [PubMed]

61. Pisanu, S.; Palmas, V.; Madau, V.; Casula, E.; Deledda, A.; Cusano, R.; Uva, P.; Vascellari, S.; Boi, F.; Loviselli, A. Impact of a Moderately Hypocaloric Mediterranean Diet on the Gut Microbiota Composition of Italian Obese Patients. Nutrients 2020, 12, 2707. [CrossRef]

62. Pagliai, G.; Russo, E.; Niccolai, E.; Dinu, M.; Di Pilato, V.; Magrini, A.; Bartolucci, G.; Baldi, S.; Menicatti, M.; Giusti, B. Influence of a 3-month low-calorie Mediterranean diet compared to the vegetarian diet on human gut microbiota and SCFA: The CARDIVEG Study. Eur. J. Nutr. 2020, 59, 2011-2024. [CrossRef] [PubMed]

63. Dadkhah, E.; Sikaroodi, M.; Korman, L.; Hardi, R.; Baybick, J.; Hanzel, D.; Kuehn, G.; Kuehn, T.; Gillevet, P.M. Gut microbiome identifies risk for colorectal polyps. BMJ Open Gastroenterol. 2019, 6, e000297. [CrossRef]

64. De Filippis, F.; Pellegrini, N.; Vannini, L.; Jeffery, I.B.; La Storia, A.; Laghi, L.; Serrazanetti, D.I.; Di Cagno, R.; Ferrocino, I.; Lazzi, C. High-level adherence to a Mediterranean diet beneficially impacts the gut microbiota and associated metabolome. Gut 2016, 65, 1812-1821. [CrossRef]

65. Zackular, J.P.; Rogers, M.A.; Ruffin, M.T.; Schloss, P.D. The human gut microbiome as a screening tool for colorectal cancer. Cancer Prev. Res. 2014, 7, 1112-1121. [CrossRef]

66. Zeller, G.; Tap, J.; Voigt, A.Y.; Sunagawa, S.; Kultima, J.R.; Costea, P.I.; Amiot, A.; Böhm, J.; Brunetti, F.; Habermann, N. Potential of fecal microbiota for early-stage detection of colorectal cancer. Mol. Syst. Biol. 2014, 10, 766. [CrossRef]

67. Pearson, T.; Caporaso, J.G.; Yellowhair, M.; Bokulich, N.A.; Padi, M.; Roe, D.J.; Wertheim, B.C.; Linhart, M.; Martinez, J.A.; Bilagody, C. Effects of ursodeoxycholic acid on the gut microbiome and colorectal adenoma development. Cancer Med. 2019, 8 , 617-628. [CrossRef] [PubMed]

68. Shin, N.-R.; Whon, T.W.; Bae, J.-W. Proteobacteria: Microbial signature of dysbiosis in gut microbiota. Trends Biotechnol. 2015, 33, 496-503. [CrossRef]

69. Elabd, E.M.Y.; Morsy, S.M.; Elmalt, H.A. Investigating of Moringa oleifera role on Gut microbiota composition and inflammation associated with obesity following high fat diet feeding. Open Access Maced. J. Med. Sci. 2018, 6, 1359. [CrossRef]

70. Prieto, I.; Hidalgo, M.; Segarra, A.B.; Martínez-Rodríguez, A.M.; Cobo, A.; Ramírez, M.; Abriouel, H.; Gálvez, A.; MartínezCañamero, M. Influence of a diet enriched with virgin olive oil or butter on mouse gut microbiota and its correlation to physiological and biochemical parameters related to metabolic syndrome. PLoS ONE 2018, 13, e0190368. [CrossRef]

71. Jakobsson, H.E.; Rodríguez-Piñeiro, A.M.; Schütte, A.; Ermund, A.; Boysen, P.; Bemark, M.; Sommer, F.; Bäckhed, F.; Hansson, G.C.; Johansson, M.E. The composition of the gut microbiota shapes the colon mucus barrier. EMBO Rep. 2015, 16, 164-177. [CrossRef] 
72. Lupp, C.; Robertson, M.L.; Wickham, M.E.; Sekirov, I.; Champion, O.L.; Gaynor, E.C.; Finlay, B.B. Host-mediated inflammation disrupts the intestinal microbiota and promotes the overgrowth of Enterobacteriaceae. Cell Host Microbe 2007, 2, 119-129. [CrossRef]

73. Morgan, X.C.; Tickle, T.L.; Sokol, H.; Gevers, D.; Devaney, K.L.; Ward, D.V.; Reyes, J.A.; Shah, S.A.; LeLeiko, N.; Snapper, S.B. Dysfunction of the intestinal microbiome in inflammatory bowel disease and treatment. Genome Biol. 2012, 13, R79. [CrossRef]

74. Mira-Pascual, L.; Cabrera-Rubio, R.; Ocon, S.; Costales, P.; Parra, A.; Suarez, A.; Moris, F.; Rodrigo, L.; Mira, A.; Collado, M. Microbial mucosal colonic shifts associated with the development of colorectal cancer reveal the presence of different bacterial and archaeal biomarkers. J. Gastroenterol. 2015, 50, 167-179. [CrossRef] [PubMed]

75. Byndloss, M.X.; Olsan, E.E.; Rivera-Chávez, F.; Tiffany, C.R.; Cevallos, S.A.; Lokken, K.L.; Torres, T.P.; Byndloss, A.J.; Faber, F.; Gao, Y. Microbiota-activated PPAR- $\gamma$ signaling inhibits dysbiotic Enterobacteriaceae expansion. Science 2017, 357, 570-575. [CrossRef] [PubMed]

76. Dinakaran, V.; Mandape, S.N.; Shuba, K.; Pratap, S.; Sakhare, S.S.; Tabatabai, M.A.; Smoot, D.T.; Farmer-Dixon, C.M.; Kesavalu, L.N.; Adunyah, S.E. Identification of specific oral and gut pathogens in full thickness colon of colitis patients: Implications for colon motility. Front. Microbiol. 2019, 9, 3220. [CrossRef] [PubMed]

77. De Cruz, P.; Kang, S.; Wagner, J.; Buckley, M.; Sim, W.H.; Prideaux, L.; Lockett, T.; McSweeney, C.; Morrison, M.; Kirkwood, C.D. Association between specific mucosa-associated microbiota in Crohn's disease at the time of resection and subsequent disease recurrence: A pilot study. J. Gastroenterol. Hepatol. 2015, 30, 268-278. [CrossRef]

78. Richard, M.L.; Liguori, G.; Lamas, B.; Brandi, G.; da Costa, G.; Hoffmann, T.W.; Pierluigi Di Simone, M.; Calabrese, C.; Poggioli, G.; Langella, P. Mucosa-associated microbiota dysbiosis in colitis associated cancer. Gut Microbes 2018, 9, 131-142. [CrossRef]

79. Group, E.S. An international association between Helicobacter pylori infection and gastric cancer. Lancet 1993, 341, 1359-1363. [CrossRef]

80. Baj, J.; Korona-Głowniak, I.; Forma, A.; Maani, A.; Sitarz, E.; Rahnama-Hezavah, M.; Radzikowska, E.; Portincasa, P. Mechanisms of the Epithelial-Mesenchymal Transition and Tumor Microenvironment in Helicobacter pylori-Induced Gastric Cancer. Cells 2020, 9, 1055. [CrossRef]

81. Maeda, M.; Moro, H.; Ushijima, T. Mechanisms for the induction of gastric cancer by Helicobacter pylori infection: Aberrant DNA methylation pathway. Gastric Cancer 2017, 20, 8-15. [CrossRef]

82. Matsumoto, Y.; Marusawa, H.; Kinoshita, K.; Endo, Y.; Kou, T.; Morisawa, T.; Azuma, T.; Okazaki, I.-M.; Honjo, T.; Chiba, T. Helicobacter pylori infection triggers aberrant expression of activation-induced cytidine deaminase in gastric epithelium. Nat. Med. 2007, 13, 470-476. [CrossRef]

83. Meucci, G.; Tatarella, M.; Vecchi, M.; Ranzi, M.; Biguzzi, E.; Beccari, G.; Clerici, E.; De Franchis, R. High prevalence of Helicobacter pylori infection in patients with colonic adenomas and carcinomas. J. Clin. Gastroenterol. 1997, 25, 605-607. [CrossRef] [PubMed]

84. Strofilas, A.; Lagoudianakis, E.E.; Seretis, C.; Pappas, A.; Koronakis, N.; Keramidaris, D.; Koukoutsis, I.; Chrysikos, I.; Manouras, I.; Manouras, A. Association of helicobacter pylori infection and colon cancer. J. Clin. Med. Res. 2012, 4, 172. [CrossRef] [PubMed]

85. Maggio-Price, L.; Treuting, P.; Zeng, W.; Tsang, M.; Bielefeldt-Ohmann, H.; Iritani, B.M. Helicobacter infection is required for inflammation and colon cancer in SMAD3-deficient mice. Cancer Res. 2006, 66, 828-838. [CrossRef] [PubMed]

86. Brennan, C.A.; Garrett, W.S. Fusobacterium nucleatum-Symbiont, opportunist and oncobacterium. Nat. Rev. Microbiol. 2019, 17, 156-166. [CrossRef] [PubMed]

87. Castellarin, M.; Warren, R.L.; Freeman, J.D.; Dreolini, L.; Krzywinski, M.; Strauss, J.; Barnes, R.; Watson, P.; Allen-Vercoe, E.; Moore, R.A. Fusobacterium nucleatum infection is prevalent in human colorectal carcinoma. Genome Res. 2012, 22, $299-306$. [CrossRef] [PubMed]

88. Strauss, J.; Kaplan, G.G.; Beck, P.L.; Rioux, K.; Panaccione, R.; DeVinney, R.; Lynch, T.; Allen-Vercoe, E. Invasive potential of gut mucosa-derived Fusobacterium nucleatum positively correlates with IBD status of the host. Inflamm. Bowel Dis. 2011, 17, 1971-1978. [CrossRef]

89. Rubinstein, M.R.; Wang, X.; Liu, W.; Hao, Y.; Cai, G.; Han, Y.W. Fusobacterium nucleatum promotes colorectal carcinogenesis by modulating E-cadherin/ $\beta$-catenin signaling via its FadA adhesin. Cell Host Microbe 2013, 14, 195-206. [CrossRef]

90. Gur, C.; Ibrahim, Y.; Isaacson, B.; Yamin, R.; Abed, J.; Gamliel, M.; Enk, J.; Bar-On, Y.; Stanietsky-Kaynan, N.; Coppenhagen-Glazer, $\mathrm{S}$. Binding of the Fap2 protein of Fusobacterium nucleatum to human inhibitory receptor TIGIT protects tumors from immune cell attack. Immunity 2015, 42, 344-355. [CrossRef]

91. Kostic, A.D.; Chun, E.; Robertson, L.; Glickman, J.N.; Gallini, C.A.; Michaud, M.; Clancy, T.E.; Chung, D.C.; Lochhead, P.; Hold, G.L. Fusobacterium nucleatum potentiates intestinal tumorigenesis and modulates the tumor-immune microenvironment. Cell Host Microbe 2013, 14, 207-215. [CrossRef]

92. Cao, P.; Chen, Y.; Chen, Y.; Su, W.; Zhan, N.; Dong, W. Fusobacterium nucleatum activates endoplasmic reticulum stress to promote crohn's disease development via the upregulation of CARD3 expression. Front. Pharmacol. 2020, 11, 106. [CrossRef]

93. Tahara, T.; Hirata, I.; Nakano, N.; Tahara, S.; Horiguchi, N.; Kawamura, T.; Okubo, M.; Ishizuka, T.; Yamada, H.; Yoshida, D. Potential link between Fusobacterium enrichment and DNA methylation accumulation in the inflammatory colonic mucosa in ulcerative colitis. Oncotarget 2017, 8, 61917. [CrossRef]

94. Mehta, R.S.; Nishihara, R.; Cao, Y.; Song, M.; Mima, K.; Qian, Z.R.; Nowak, J.A.; Kosumi, K.; Hamada, T.; Masugi, Y. Association of dietary patterns with risk of colorectal cancer subtypes classified by Fusobacterium nucleatum in tumor tissue. JAMA Oncol. 2017, 3, 921-927. [CrossRef] [PubMed] 
95. O'Keefe, S.J.; Li, J.V.; Lahti, L.; Ou, J.; Carbonero, F.; Mohammed, K.; Posma, J.M.; Kinross, J.; Wahl, E.; Ruder, E. Fat, fibre and cancer risk in African Americans and rural Africans. Nat. Commun. 2015, 6, 1-14. [CrossRef] [PubMed]

96. Jangi, S.; Gandhi, R.; Cox, L.M.; Li, N.; Von Glehn, F.; Yan, R.; Patel, B.; Mazzola, M.A.; Liu, S.; Glanz, B.L. Alterations of the human gut microbiome in multiple sclerosis. Nat. Commun. 2016, 7, 1-11. [CrossRef] [PubMed]

97. Hibberd, A.A.; Lyra, A.; Ouwehand, A.C.; Rolny, P.; Lindegren, H.; Cedgård, L.; Wettergren, Y. Intestinal microbiota is altered in patients with colon cancer and modified by probiotic intervention. BMJ Open Gastroenterol. 2017, 4, e000145. [CrossRef]

98. Million, M.; Maraninchi, M.; Henry, M.; Armougom, F.; Richet, H.; Carrieri, P.; Valero, R.; Raccah, D.; Vialettes, B.; Raoult, D. Obesity-associated gut microbiota is enriched in Lactobacillus reuteri and depleted in Bifidobacterium animalis and Methanobrevibacter smithii. Int. J. Obes. 2012, 36, 817-825. [CrossRef]

99. Picchianti Diamanti, A.; Panebianco, C.; Salerno, G.; Di Rosa, R.; Salemi, S.; Sorgi, M.L.; Meneguzzi, G.; Mariani, M.B.; Rai, A.; Iacono, D. Impact of Mediterranean Diet on Disease Activity and Gut Microbiota Composition of Rheumatoid Arthritis Patients. Microorganisms 2020, 8, 1989. [CrossRef]

100. Garcia-Mantrana, I.; Selma-Royo, M.; Alcantara, C.; Collado, M.C. Shifts on gut microbiota associated to mediterranean diet adherence and specific dietary intakes on general adult population. Front. Microbiol. 2018, 9, 890. [CrossRef]

101. van de Pol, J.A.; van Best, N.; Mbakwa, C.A.; Thijs, C.; Savelkoul, P.H.; Arts, I.C.; Hornef, M.W.; Mommers, M.; Penders, J. Gut colonization by methanogenic archaea is associated with organic dairy consumption in children. Front. Microbiol. $2017,8,355$. [CrossRef]

102. Hustoft, T.; Hausken, T.; Ystad, S.; Valeur, J.; Brokstad, K.; Hatlebakk, J.; Lied, G. Effects of varying dietary content of fermentable short-chain carbohydrates on symptoms, fecal microenvironment, and cytokine profiles in patients with irritable bowel syndrome. Neurogastroenterol. Motil. 2017, 29, e12969. [CrossRef]

103. Miyamoto, J.; Watanabe, K.; Taira, S.; Kasubuchi, M.; Li, X.; Irie, J.; Itoh, H.; Kimura, I. Barley $\beta$-glucan improves metabolic condition via short-chain fatty acids produced by gut microbial fermentation in high fat diet fed mice. PLoS ONE 2018, 13, e0196579. [CrossRef]

104. Vinolo, M.A.; Rodrigues, H.G.; Nachbar, R.T.; Curi, R. Regulation of inflammation by short chain fatty acids. Nutrients 2011, 3 , 858-876. [CrossRef] [PubMed]

105. Leahy, S.; Higgins, D.; Fitzgerald, G.; Van Sinderen, D. Getting better with bifidobacteria. J. Appl. Microbiol. 2005, 98, 1303-1315. [CrossRef]

106. Mayo, B.; Vázquez, L.; Flórez, A.B. Equol: A bacterial metabolite from the daidzein isoflavone and its presumed beneficial health effects. Nutrients 2019, 11, 2231. [CrossRef] [PubMed]

107. Atkinson, C.; Frankenfeld, C.L.; Lampe, J.W. Gut bacterial metabolism of the soy isoflavone daidzein: Exploring the relevance to human health. Exp. Biol. Med. 2005, 230, 155-170. [CrossRef]

108. Setchell, K.D.; Cole, S.J. Method of defining equol-producer status and its frequency among vegetarians. J. Nutr. 2006, 136, 2188-2193. [CrossRef] [PubMed]

109. Caesar, R.; Tremaroli, V.; Kovatcheva-Datchary, P.; Cani, P.D.; Bäckhed, F. Crosstalk between gut microbiota and dietary lipids aggravates WAT inflammation through TLR signaling. Cell Metab. 2015, 22, 658-668. [CrossRef]

110. Sartor, R.B.; Mazmanian, S.K. Intestinal microbes in inflammatory bowel diseases. Am. J. Gastroenterol. Suppl. $2012,1,15$. [CrossRef]

111. Gomez-Arango, L.F.; Barrett, H.L.; Wilkinson, S.A.; Callaway, L.K.; McIntyre, H.D.; Morrison, M.; Dekker Nitert, M. Low dietary fiber intake increases Collinsella abundance in the gut microbiota of overweight and obese pregnant women. Gut Microbes 2018, 9, 189-201. [CrossRef]

112. Astbury, S.; Atallah, E.; Vijay, A.; Aithal, G.P.; Grove, J.I.; Valdes, A.M. Lower gut microbiome diversity and higher abundance of proinflammatory genus Collinsella are associated with biopsy-proven nonalcoholic steatohepatitis. Gut Microbes 2020, 11, 569-580. [CrossRef] [PubMed]

113. Chen, J.; Wright, K.; Davis, J.M.; Jeraldo, P.; Marietta, E.V.; Murray, J.; Nelson, H.; Matteson, E.L.; Taneja, V. An expansion of rare lineage intestinal microbes characterizes rheumatoid arthritis. Genome Med. 2016, 8, 1-14. [CrossRef]

114. Nagpal, R.; Neth, B.J.; Wang, S.; Craft, S.; Yadav, H. Modified Mediterranean-ketogenic diet modulates gut microbiome and short-chain fatty acids in association with Alzheimer's disease markers in subjects with mild cognitive impairment. EBioMedicine 2019, 47, 529-542. [CrossRef] [PubMed]

115. Jin, J.-S.; Kitahara, M.; Sakamoto, M.; Hattori, M.; Benno, Y. Slackia equolifaciens sp. nov., a human intestinal bacterium capable of producing equol. Int. J. Syst. Evol. Microbiol. 2010, 60, 1721-1724. [CrossRef]

116. Matthies, A.; Loh, G.; Blaut, M.; Braune, A. Daidzein and genistein are converted to equol and 5-hydroxy-equol by human intestinal Slackia isoflavoniconvertens in gnotobiotic rats. J. Nutr. 2012, 142, 40-46. [CrossRef]

117. Kim, K.-S.; Rowlinson, M.-C.; Bennion, R.; Liu, C.; Talan, D.; Summanen, P.; Finegold, S.M. Characterization of Slackia exigua isolated from human wound infections, including abscesses of intestinal origin. J. Clin. Microbiol. 2010, 48, 1070-1075. [CrossRef]

118. Albertsen, M.; Hugenholtz, P.; Skarshewski, A.; Nielsen, K.L.; Tyson, G.W.; Nielsen, P.H. Genome sequences of rare, uncultured bacteria obtained by differential coverage binning of multiple metagenomes. Nat. Biotechnol. 2013, 31, 533-538. [CrossRef]

119. Kuehbacher, T.; Rehman, A.; Lepage, P.; Hellmig, S.; Fölsch, U.R.; Schreiber, S.; Ott, S.J. Intestinal TM7 bacterial phylogenies in active inflammatory bowel disease. J. Med Microbiol. 2008, 57, 1569-1576. [CrossRef] 
120. He, X.; McLean, J.S.; Edlund, A.; Yooseph, S.; Hall, A.P.; Liu, S.-Y.; Dorrestein, P.C.; Esquenazi, E.; Hunter, R.C.; Cheng, G. Cultivation of a human-associated TM7 phylotype reveals a reduced genome and epibiotic parasitic lifestyle. Proc. Natl. Acad. Sci. USA 2015, 112, 244-249. [CrossRef] [PubMed]

121. Louis, P.; Flint, H.J. Formation of propionate and butyrate by the human colonic microbiota. Environ. Microbiol. 2017, 19, 29-41. [CrossRef]

122. Png, C.W.; Lindén, S.K.; Gilshenan, K.S.; Zoetendal, E.G.; McSweeney, C.S.; Sly, L.I.; McGuckin, M.A.; Florin, T.H. Mucolytic Bacteria With Increased Prevalence in IBD Mucosa AugmentIn VitroUtilization of Mucin by Other Bacteria. Am. J. Gastroenterol. 2010, 105, 2420-2428. [CrossRef] [PubMed]

123. Henke, M.T.; Kenny, D.J.; Cassilly, C.D.; Vlamakis, H.; Xavier, R.J.; Clardy, J. Ruminococcus gnavus, a member of the human gut microbiome associated with Crohn's disease, produces an inflammatory polysaccharide. Proc. Natl. Acad. Sci. USA 2019, 116, 12672-12677. [CrossRef]

124. Hall, A.B.; Yassour, M.; Sauk, J.; Garner, A.; Jiang, X.; Arthur, T.; Lagoudas, G.K.; Vatanen, T.; Fornelos, N.; Wilson, R. A novel Ruminococcus gnavus clade enriched in inflammatory bowel disease patients. Genome Med. 2017, 9, 1-12. [CrossRef] [PubMed]

125. Machiels, K.; Joossens, M.; Sabino, J.; De Preter, V.; Arijs, I.; Eeckhaut, V.; Ballet, V.; Claes, K.; Van Immerseel, F.; Verbeke, K. A decrease of the butyrate-producing species Roseburia hominis and Faecalibacterium prausnitzii defines dysbiosis in patients with ulcerative colitis. Gut 2014, 63, 1275-1283. [CrossRef] [PubMed]

126. Quan, Y.; Song, K.; Zhang, Y.; Zhu, C.; Shen, Z.; Wu, S.; Luo, W.; Tan, B.; Yang, Z.; Wang, X. Roseburia intestinalis-derived flagellin is a negative regulator of intestinal inflammation. Biochem. Biophys. Res. Commun. 2018, 501, 791-799. [CrossRef]

127. Wang, T.; Cai, G.; Qiu, Y.; Fei, N.; Zhang, M.; Pang, X.; Jia, W.; Cai, S.; Zhao, L. Structural segregation of gut microbiota between colorectal cancer patients and healthy volunteers. ISME J. 2012, 6, 320-329. [CrossRef] [PubMed]

128. Menni, C.; Hernandez, M.M.; Vital, M.; Mohney, R.P.; Spector, T.D.; Valdes, A.M. Circulating levels of the anti-oxidant indoleproprionic acid are associated with higher gut microbiome diversity. Gut Microbes 2019, 10, 688-695. [CrossRef]

129. Negatu, D.A.; Gengenbacher, M.; Dartois, V.A.; Dick, T. Indole propionic acid, an unusual antibiotic produced by the gut microbiota, with anti-inflammatory and antioxidant properties. Front. Microbiol. 2020, 11, 2654. [CrossRef]

130. Bang, S.-J.; Kim, G.; Lim, M.Y.; Song, E.-J.; Jung, D.-H.; Kum, J.-S.; Nam, Y.-D.; Park, C.-S.; Seo, D.-H. The influence of in vitro pectin fermentation on the human fecal microbiome. Amb Express 2018, 8, 1-9. [CrossRef]

131. De Angelis, M.; Ferrocino, I.; Calabrese, F.M.; De Filippis, F.; Cavallo, N.; Siragusa, S.; Rampelli, S.; Di Cagno, R.; Rantsiou, K.; Vannini, L. Diet influences the functions of the human intestinal microbiome. Sci. Rep. 2020, 10, 4247. [CrossRef]

132. Schreiner, P.; Yilmaz, B.; Rossel, J.-B.; Franc, Y.; Misselwitz, B.; Scharl, M.; Zeitz, J.; Frei, P.; Greuter, T.; Vavricka, S.R. Vegetarian or gluten-free diets in patients with inflammatory bowel disease are associated with lower psychological well-being and a different gut microbiota, but no beneficial effects on the course of the disease. United Eur. Gastroenterol. J. 2019, 7, 767-781. [CrossRef]

133. Chávez-Carbajal, A.; Nirmalkar, K.; Pérez-Lizaur, A.; Hernández-Quiroz, F.; Ramírez-del-Alto, S.; García-Mena, J.; HernándezGuerrero, C. Gut microbiota and predicted metabolic pathways in a sample of Mexican women affected by obesity and obesity plus metabolic syndrome. Int. J. Mol. Sci. 2019, 20, 438. [CrossRef]

134. Liu, R.; Hong, J.; Xu, X.; Feng, Q.; Zhang, D.; Gu, Y.; Shi, J.; Zhao, S.; Liu, W.; Wang, X. Gut microbiome and serum metabolome alterations in obesity and after weight-loss intervention. Nat. Med. 2017, 23, 859. [CrossRef]

135. Benítez-Páez, A.; Del Pugar, E.M.G.; López-Almela, I.; Moya-Pérez, Á.; Codoñer-Franch, P.; Sanz, Y. Depletion of Blautia species in the microbiota of obese children relates to intestinal inflammation and metabolic phenotype worsening. Msystems 2020, 5, e00857-19. [CrossRef] [PubMed]

136. Kolenbrander, P. The genus Veillonella. Prokaryotes 2006, 4, 1022-1040.

137. Louis, P.; Hold, G.L.; Flint, H.J. The gut microbiota, bacterial metabolites and colorectal cancer. Nat. Rev. Microbiol. 2014, 12, 661-672. [CrossRef] [PubMed]

138. Del Dot, T.; Osawa, R.; Stackebrandt, E. Phascolarctobacterium faecium gen. nov, spec. nov., a novel taxon of the Sporomusa group of bacteria. Syst. Appl. Microbiol. 1993, 16, 380-384. [CrossRef]

139. Watanabe, Y.; Nagai, F.; Morotomi, M. Characterization of Phascolarctobacterium succinatutens sp. nov., an asaccharolytic, succinateutilizing bacterium isolated from human feces. Appl. Environ. Microbiol. 2012, 78, 511-518. [CrossRef]

140. Kes, M.M.; Van den Bossche, J.; Griffioen, A.W.; Huijbers, E.J. Oncometabolites lactate and succinate drive pro-angiogenic macrophage response in tumors. Biochim. Biophys. Acta Rev. Cancer 2020, 1874, 188427. [CrossRef]

141. Tannahill, G.; Curtis, A.; Adamik, J.; Palsson-McDermott, E.; McGettrick, A.; Goel, G.; Frezza, C.; Bernard, N.; Kelly, B.; Foley, N. Succinate is an inflammatory signal that induces IL-1 $\beta$ through HIF-1 $\alpha$. Nature 2013, 496, 238-242. [CrossRef] [PubMed]

142. Vernia, P.; Caprilli, R.; Latella, G.; Barbetti, F.; Magliocca, F.M.; Cittadini, M. Fecal lactate and ulcerative colitis. Gastroenterology 1988, 95, 1564-1568. [CrossRef]

143. Barrett, H.L.; Gomez-Arango, L.F.; Wilkinson, S.A.; McIntyre, H.D.; Callaway, L.K.; Morrison, M.; Dekker Nitert, M. A vegetarian diet is a major determinant of gut microbiota composition in early pregnancy. Nutrients 2018, 10, 890. [CrossRef] [PubMed]

144. Whisner, C.M.; Martin, B.R.; Nakatsu, C.H.; Story, J.A.; MacDonald-Clarke, C.J.; McCabe, L.D.; McCabe, G.P.; Weaver, C.M. Soluble corn fiber increases calcium absorption associated with shifts in the gut microbiome: A randomized dose-response trial in free-living pubertal females. J. Nutr. 2016, 146, 1298-1306. [CrossRef] 
145. Martínez, I.; Lattimer, J.M.; Hubach, K.L.; Case, J.A.; Yang, J.; Weber, C.G.; Louk, J.A.; Rose, D.J.; Kyureghian, G.; Peterson, D.A. Gut microbiome composition is linked to whole grain-induced immunological improvements. ISME J. 2013, 7, 269-280. [CrossRef]

146. Citronberg, J.S.; Curtis, K.R.; White, E.; Newcomb, P.A.; Newton, K.; Atkinson, C.; Song, X.; Lampe, J.W.; Hullar, M.A. Association of gut microbial communities with plasma lipopolysaccharide-binding protein (LBP) in premenopausal women. ISME J. 2018, 12, 1631-1641. [CrossRef]

147. Bajer, L.; Kverka, M.; Kostovcik, M.; Macinga, P.; Dvorak, J.; Stehlikova, Z.; Brezina, J.; Wohl, P.; Spicak, J.; Drastich, P. Distinct gut microbiota profiles in patients with primary sclerosing cholangitis and ulcerative colitis. World J. Gastroenterol. 2017, $23,4548$. [CrossRef]

148. Weir, T.L.; Manter, D.K.; Sheflin, A.M.; Barnett, B.A.; Heuberger, A.L.; Ryan, E.P. Stool microbiome and metabolome differences between colorectal cancer patients and healthy adults. PLoS ONE 2013, 8, e70803. [CrossRef]

149. Yachida, S.; Mizutani, S.; Shiroma, H.; Shiba, S.; Nakajima, T.; Sakamoto, T.; Watanabe, H.; Masuda, K.; Nishimoto, Y.; Kubo, M. Metagenomic and metabolomic analyses reveal distinct stage-specific phenotypes of the gut microbiota in colorectal cancer. Nat. Med. 2019, 25, 968-976. [CrossRef]

150. Matera, G.; Muto, V.; Vinci, M.; Zicca, E.; Abdollahi-Roodsaz, S.; van de Veerdonk, F.L.; Kullberg, B.-J.; Liberto, M.C.; van der Meer, J.W.; Foca, A. Receptor recognition of and immune intracellular pathways for Veillonella parvula lipopolysaccharide. Clin. Vaccine Immunol. 2009, 16, 1804-1809. [CrossRef] [PubMed]

151. van den Bogert, B.; Meijerink, M.; Zoetendal, E.G.; Wells, J.M.; Kleerebezem, M. Immunomodulatory properties of Streptococcus and Veillonella isolates from the human small intestine microbiota. PLoS ONE 2014, 9, e114277. [CrossRef] [PubMed]

152. Santoru, M.L.; Piras, C.; Murgia, A.; Palmas, V.; Camboni, T.; Liggi, S.; Ibba, I.; Lai, M.A.; Orrù, S.; Blois, S. Cross sectional evaluation of the gut-microbiome metabolome axis in an Italian cohort of IBD patients. Sci. Rep. 2017, 7, 9523. [CrossRef] [PubMed]

153. Gevers, D.; Kugathasan, S.; Denson, L.A.; Vázquez-Baeza, Y.; Van Treuren, W.; Ren, B.; Schwager, E.; Knights, D.; Song, S.J.; Yassour, M. The treatment-naive microbiome in new-onset Crohn's disease. Cell Host Microbe 2014, 15, 382-392. [CrossRef]

154. Russell, J.B. Acidaminococcus. In Bergey's Manual of Systematics of Archaea and Bacteria; John Wiley \& Sons, Inc.: Hoboken, NJ, USA, 2015; pp. 1-3.

155. Marchandin, H.; Juvonen, R.; Haikara, A. Megasphaera. In Bergey's Manual of Systematics of Archaea and Bacteria; John Wiley \& Sons, Inc.: Hoboken, NJ, USA, 2015; pp. 1-16.

156. Willems, A.; Collins, M.D. Mitsuokella. In Bergey's Manual of Systematics of Archaea and Bacteria; John Wiley \& Sons, Inc.: Hoboken, NJ, USA, 2015; pp. 1-9.

157. Dai, Z.-L.; Zhang, J.; Wu, G.; Zhu, W.-Y. Utilization of amino acids by bacteria from the pig small intestine. Amino Acids 2010, 39, 1201-1215. [CrossRef] [PubMed]

158. Han, S.-W.; Chee, K.-M.; Cho, S.-J. Nutritional quality of rice bran protein in comparison to animal and vegetable protein. Food Chem. 2015, 172, 766-769. [CrossRef] [PubMed]

159. Belzer, C.; De Vos, W.M. Microbes inside-From diversity to function: The case of Akkermansia. ISME J. 2012, 6, 1449-1458. [CrossRef] [PubMed]

160. Earley, H.; Lennon, G.; Balfe, Á.; Coffey, J.C.; Winter, D.C.; O'Connell, P.R. The abundance of Akkermansia muciniphila and its relationship with sulphated colonic mucins in health and ulcerative colitis. Sci. Rep. 2019, 9, 15683. [CrossRef] [PubMed]

161. Ghosh, S.S.; Wang, J.; Yannie, P.J.; Sandhu, Y.K.; Korzun, W.J.; Ghosh, S. Dietary supplementation with galactooligosaccharides attenuates high-fat, high-cholesterol diet-induced glucose intolerance and disruption of colonic mucin layer in C57BL/6 mice and reduces atherosclerosis in Ldlr-/-mice. J. Nutr. 2020, 150, 285-293. [CrossRef]

162. Hashemi, Z.; Fouhse, J.; Im, H.S.; Chan, C.B.; Willing, B.P. Dietary pea fiber supplementation improves glycemia and induces changes in the composition of gut microbiota, serum short chain fatty acid profile and expression of mucins in glucose intolerant rats. Nutrients 2017, 9, 1236. [CrossRef]

163. Sanapareddy, N.; Legge, R.M.; Jovov, B.; McCoy, A.; Burcal, L.; Araujo-Perez, F.; Randall, T.A.; Galanko, J.; Benson, A.; Sandler, R.S. Increased rectal microbial richness is associated with the presence of colorectal adenomas in humans. ISME J. 2012, 6, 1858-1868. [CrossRef]

164. Byrd, J.C.; Bresalier, R.S. Mucins and mucin binding proteins in colorectal cancer. Cancer Metastasis Rev. 2004, 23, 77-99. [CrossRef]

165. Betge, J.; Schneider, N.I.; Harbaum, L.; Pollheimer, M.J.; Lindtner, R.A.; Kornprat, P.; Ebert, M.P.; Langner, C. MUC1, MUC2, MUC5AC, and MUC6 in colorectal cancer: Expression profiles and clinical significance. Virchows Arch. 2016, 469, 255-265. [CrossRef]

166. Wu, M.; Wu, Y.; Li, J.; Bao, Y.; Guo, Y.; Yang, W. The dynamic changes of gut microbiota in Muc2 deficient mice. Int. J. Mol. Sci. 2018, 19, 2809. [CrossRef]

167. Liso, M.; De Santis, S.; Verna, G.; Dicarlo, M.; Calasso, M.; Santino, A.; Gigante, I.; Eri, R.; Raveenthiraraj, S.; Sobolewski, A. A specific mutation in Muc2 determines early dysbiosis in colitis-prone Winnie mice. Inflamm. Bowel Dis. 2020, $26,546-556$. [CrossRef] [PubMed]

168. Lepage, P.; Häsler, R.; Spehlmann, M.E.; Rehman, A.; Zvirbliene, A.; Begun, A.; Ott, S.; Kupcinskas, L.; Doré, J.; Raedler, A. Twin study indicates loss of interaction between microbiota and mucosa of patients with ulcerative colitis. Gastroenterology 2011, 141, 227-236. [CrossRef] [PubMed] 
169. Pianta, A.; Arvikar, S.; Strle, K.; Drouin, E.E.; Wang, Q.; Costello, C.E.; Steere, A.C. Evidence of the immune relevance of Prevotella copri, a gut microbe, in patients with rheumatoid arthritis. Arthritis Rheumatol. 2017, 69, 964-975. [CrossRef]

170. Marietta, E.V.; Murray, J.A.; Luckey, D.H.; Jeraldo, P.R.; Lamba, A.; Patel, R.; Luthra, H.S.; Mangalam, A.; Taneja, V. Suppression of inflammatory arthritis by human gut-derived Prevotella histicola in humanized mice. Arthritis Rheumatol. 2016, 68, 2878-2888. [CrossRef] [PubMed]

171. Wexler, H.M. Bacteroides: The good, the bad, and the nitty-gritty. Clin. Microbiol. Rev. 2007, 20, 593-621. [CrossRef] [PubMed]

172. Yu, T.; Guo, F.; Yu, Y.; Sun, T.; Ma, D.; Han, J.; Qian, Y.; Kryczek, I.; Sun, D.; Nagarsheth, N. Fusobacterium nucleatum promotes chemoresistance to colorectal cancer by modulating autophagy. Cell 2017, 170, 548-563.e16. [CrossRef] [PubMed]

173. Microbiome CRC Biomarker Study. Available online: http:/ / mothur.org/MicrobiomeBiomarkerCRC (accessed on 10 June 2020). 